\title{
Neurovascular Unit as a Source of Ischemic Stroke Biomarkers-Limitations of Experimental Studies and Perspectives for Clinical Application
}

\author{
Aleksandra Steliga $^{1} \cdot$ Przemysław Kowiański $^{1,2}$ (D) Ewelina Czuba ${ }^{2} \cdot$ Monika Waśkow $^{1} \cdot$ Janusz Moryśs $^{2} \cdot$ \\ Grażyna Lietzau ${ }^{2,3}$
}

Received: 15 March 2019 / Revised: 23 September 2019 / Accepted: 24 September 2019 / Published online: 7 November 2019

(C) The Author(s) 2019

\begin{abstract}
Cerebral stroke, which is one of the most frequent causes of mortality and leading cause of disability in developed countries, often leads to devastating and irreversible brain damage. Neurological and neuroradiological diagnosis of stroke, especially in its acute phase, is frequently uncertain or inconclusive. This results in difficulties in identification of patients with poor prognosis or being at high risk for complications. It also makes difficult identification of these stroke patients who could benefit from more aggressive therapies. In contrary to the cardiovascular disease, no single biomarker is available for the ischemic stroke, addressing the abovementioned issues. This justifies the need for identifying of effective diagnostic measures characterized by high specificity and sensitivity. One of the promising avenues in this area is studies on the panels of biomarkers characteristic for processes which occur in different types and phases of ischemic stroke and represent all morphological constituents of the brains' neurovascular unit (NVU). In this review, we present the current state of knowledge concerning already-used or potentially applicable biomarkers of the ischemic stroke. We also discuss the perspectives for identification of biomarkers representative for different types and phases of the ischemic stroke, as well as for different constituents of NVU, which concentration levels correlate with extent of brain damage and patients' neurological status. Finally, a critical analysis of perspectives on further improvement of the ischemic stroke diagnosis is presented.
\end{abstract}

Keywords Astrocytes $\cdot$ Biomarkers $\cdot$ Neuroglia $\cdot$ Neurovascular unit $\cdot$ Stroke

\section{Introduction}

Despite constantly increasing understanding of ischemic stroke pathophysiology, resulting among others from laboratory and clinical studies, improvement of neuroradiological imaging technics, better understanding of the significance of risk factors and application to clinical practice the results of large population studies, diagnosis of acute stroke is

Przemysław Kowiański

kowiansk@gumed.edu.pl

1 Faculty of Health Sciences, Pomeranian University of Slupsk, 64 Bohaterów Westerplatte St., 76-200 Slupsk, Poland

2 Department of Anatomy and Neurobiology, Medical University of Gdansk, 1 Debinki St., 80-211 Gdansk, Poland

3 Department of Clinical Science and Education, Södersjukhuset, Internal Medicine, Karolinska Institutet, Stockholm, Sweden frequently very difficult. An improvement of the organization of stroke centers and emergency transport has resulted in a significant reduction of door-to-needle time. However, despite the efforts made, this does not concern all countries and all stroke centers. In fact, a significant proportion of stroke patients still arrive to the hospital and are diagnosed late or even too late to start thrombolytic therapy [1]. The problem of the effective, fast, and precise diagnosis remains a serious challenge. In addition, as confirmed by numerous publications, in the earliest period of ischemic stroke, its diagnosis, even applying the most advanced neuroradiological methods, is frequently difficult or impossible. The results of magnetic resonanse imaging (MRI) and computer tomography (CT) studies conducted within $24 \mathrm{~h}$ from the symptoms onset even by the experienced neuroradiologists are often inconclusive. Inability to precisely diagnose a patient in the early phase of ischemic stroke may reach even $30 \%$ of cases [2]. Despite the advances in organization of stroke treatment, there is a number of cases that can create diagnostic difficulties [3, 4]. This can 
result from lack of the characteristic symptoms (also stroke mimics), assessment by non-specialists (at the pre-hospital phase or during transport), normal CT image, inaccessibility of neuroradiological equipment such as MRI or angiography, and, finally, in cases where documentation of the disease is incomplete (patient's history is missing, onset of symptoms is unknown, clinical examination is incomplete). In such cases, use of diagnostic tests based on biomarkers' panels would be rationally justified. Thus, this creates a gap for introduction of simple, not expensive, and reliable diagnostic methods, including these based on use of the neurovascular unit (NVU)derived biomarkers, being in a focus of this review. Taking into account 4.5 -h length of the therapeutic window, accepted for introduction of the thrombolytic therapy, fast and reliable diagnosis of ischemic stroke has unquestionable practical significance. The gold standard and the goal of searching for the optimal biomarker of an ischemic infarct is a sensitive substance that is objectively measured and evaluated as an indicator of physiological and pathological processes, which is specific for a given type of stroke, which content increases during a specific period of time after the symptoms' onset and reflects responses to therapeutic interventions [5]. The biomarker's value is also determined by its availability for diagnostic purposes, being a consequence of its presence in physiological fluids, such as blood or cerebrospinal fluid (CSF). Hence, our work focused on reviewing already-used, and also potential, indicators of ischemic stroke present primarily in blood serum and CSF. In addition, an attention was also paid to changes in the content of potential markers in the nervous tissue, which correlate with intensity of brain edema, assessed in neuroradiological evaluation based on MRI or positron emission tomogrphy (PET) imaging (e.g., aquaporin-4; AQP4). Despite intensive studies, so far it has not been possible to identify a single biomarker or a set of markers that would meet the expected criteria of sensitivity and specificity for detection of different types of stroke (e.g., cardioembolic, lacunar, thrombotic or large-vessel infarct, etc.) or could give a chance to predict the severity of neurological deficits, and complications or benefits resulting from different forms of implemented treatment $[4,6,7]$. All these difficulties are, at least in part, a consequence of the complex morphological structure of brain tissue and the plethora of pathophysiological processes triggered in the course of ischemic stroke [3]. Another important factor that could be responsible for failure in searching for effective ischemic biomarkers is lack of commonly accepted standardization and analytical validation of laboratory procedures, making difficult comparisons between the results obtained in different laboratories [8]. Hence, unlike the myocardial infarction, the advantages of using biochemical markers of the cerebral stroke are much more limited. Due to the fact that previously published results on potential ischemic biomarkers are inconclusive, we think it would be of some value to change the approach to this research problem and adopt some new assumptions in selection of potential markers of the ischemic process. Considering the complex structure of brain tissue and dynamic nature of processes occurring in the course of ischemia, two following issues should be taken into account during selection of markers with potential diagnostic significance: (1) the contribution of all morphological components of brain tissue to secretion of potential biomarkers; (2) the dynamic nature of pathophysiological processes occurring in the course of cerebral stroke, with their assignment to its acute, subacute, and late phases. An alternative approach is especially required for elaboration of reliable and effective diagnostic measures for stroke recognition in its acute phase. In order to improve the diagnostic effectiveness, it seems to be justified to validate the concept of NVU in the further research. The NVU has proved its unquestionable value for explanation of the mechanisms of several physiological and pathological processes in the CNS [9-11]. This morphological and functional conceptual model of the nervous tissue enables easier choice of several potential biomarkers useful for stroke evaluation and prognosis. Hence, further research should comprise the diagnostic panels, consisting of biomarkers representative not only for neurons but also for neuroglia, extracellular matrix, and elements of the blood-brain barrier (BBB) $[12,13]$. Three main components of the NVU, namely neurons, neuroglia, and brain vessels, reveal different resistance to ischemic conditions and different involvement in metabolic processes and play a different role in immune response to pathological processes occurring in the brain (e.g., cell death, brain edema, reactive gliosis, or BBB disintegration) [14]. Activation of NVU during pathological processes induces release of numerous potential biomarkers into the extracellular space, blood vessels, and CSF. Some of them are characteristic for definite cellular components, such as neurons or astrocytes, e.g., neuron-specific enolase (NSE) or glial fibrillary acidic protein (GFAP), respectively, whereas the others are released by several of them, e.g., cytokines or neurotrophic factors [8]. Altogether, development of diagnostic panels consisting of biomarkers representing all elements of the NVU and revealing the highest specificity for different phases of stroke could contribute to significant improvement of stroke diagnosis.

\section{Elements of the Neurovascular Unit in Pathophysiology of Brain Ischemia}

Deleterious effects of cerebral ischemia result from coincidence of several factors, such as time length and depth of cerebral blood flow decrease, permanent or transient character of ischemia and its localization $[15,16]$. Some anatomical features, like density of cerebral capillary vasculature or presence of collateral circulation, can also contribute to the final outcome [17]. Among consequences of ischemic stroke, 
developing within $24 \mathrm{~h}$ (acute phase) from ischemia onset, the following should be encountered: the glutamatergic excitotoxicity and raised expression of glutamate transporters [18], increased $\mathrm{Ca}^{2+}$ ion concentration, and oxidative stress, accompanied by free radical production (Fig. 1) [19, 20]. Apoptosis and necrosis can occur within the first few hours after ischemia onset and reach their peaks after $24 \mathrm{~h}$ [21]. During that time, upregulation of the apoptotic and necrotic markers and proteolytic enzymes (e.g., metalloproteinases; MMPs) occurs [22]. The BBB damage is followed by activation of the endothelial cells and pericytes [23, 24]. This is related with release of some specific markers, such as von Willebrand factor (vWF) and nerve growth factor (NGF) $[25,26]$. The BBB leakage leads to development of cerebral edema and changes in AQP4 expression in astrocytes, with its peak at 3-4 days (subacute phase) after the ischemia onset [27, 28]. The cerebral edema subsides gradually, followed by the AQP4 concentration returning to the normal level after 1 week (late phase). Activation of the inflammatory response is signalized by release of many mediators, such as cytokines and neurotrophins, predominantly non-specific for a single cellular population and produced by several constituents of the NVU. The reactive gliosis could be encountered among the subacute and late-phase phenomena [29]. It is related with neuroglial proliferation and hypertrophy, all of which are signalized by production of characteristic markers, e.g., GFAP or S100 beta $(\mathrm{S} 100 \beta)$ protein. In all these processes, astrocytes play a unique role resulting from their resistance to the reduced glucose and oxygen supply, anaerobic glycolysis, and lactate production (i.e., astrocytic-neuronal lactate shuttle), as well as resulting from the homeostatic function and immunological competence [30, 31]. Finally, brain ischemia triggers changes in expression of genes, which are involved in regulation of the structural proteins and inflammatory mediators, as well as transcription and neurotrophic factors [32, 33]. Acidosis, resulting from increased lactate level in the course of anaerobic glycolysis, as well as increased proton concentration, produced by ATP hydrolysis, is associated with activation of acid-sensing ion channels (ASICs). The increased influx of $\mathrm{Ca}^{2+}$ ions into the neurons augments the destructive $\mathrm{Ca}^{2+}$-dependent processes in the pathway which is independent from activation of glutamate receptors [34]. This mechanism has been proved to intensify neuronal damage in the course of ischemia.

As it could be inferred from this brief summary, a search for the potential ischemic biomarkers should be concentrated not only on indicators representative for neurons, but also neuroglial and endothelial cells, expressed in the acute and later phases of cerebral stroke, and activated in the course of different processes. This attitude could give a chance to screen possibly the largest spectrum of pathological processes, represented by selected markers, and provide a comprehensive information, concerning various aspects of ischemic stroke.
Choice of Potential Candidate Ischemic Stroke Biomarkers

Taking into consideration all the abovementioned issues related with the concept of NVU, a selection of the ischemic stroke biomarkers has been chosen and reviewed (Fig. 2). We focused on reviewing the most important, recognized, and potentially useful substances that can serve as biomarkers of the NVU lesion, as well as indicators of processes related to the functioning of this unit. The relationship between NVU and stroke biomarkers is not limited to the fact that specific markers are produced by different types of NVU cells. It is closely related to the integrated function of all elements of the NVU in regulation of the cerebral blood flow, BBB integrity, and permeability, as well as energetic metabolism and immunological response. Disintegration of this complicated system leads to upregulation of different biomarkers and enables their passage into blood vessels. The result being a specific profile of the biomarkers' content in the blood and CSF. This reflects the severity of tissue damage and intensity and nature of blood flow disturbance (permanent or transient) and provides information shedding light on stroke etiopathogenesis (occurrence of particular set of biomarkers). Thus, we have just started to learn the complex pathophysiological relationships within NVU, related to the production and release of ischemic stroke biomarkers. Many previous articles discuss in detail properties of the substances that are already used, or could potentially be used in the future, as new ischemic stroke biomarkers. However, a significant proportion of them are non-specific for brain tissue and are produced outside of the CNS, as a manifestation of a systemic response to brain damage, caused by decrease in blood flow, BBB damage, oxidative stress, or initiation of inflammatory processes. In this review, we have focused on biomarkers produced by components of the nervous tissue that are involved in pathophysiological processes and morphological changes occurring in the brain. In summary, this review article emphasizes the morphological and functional aspects of the relationship between NVU components, both under physiological conditions and in the course of ischemia, which result in expression changes and release of specific biomarkers from the brain tissue into the vascular system and/or CSF.

This review contains only some representatives of the extensive list of potential candidate substances (Table 1). Following, we discuss those of them which are already used in clinical practice and have a documented diagnostic significance, as well as those revealing potential usefulness, based on preliminary results of in vitro and in vivo studies, carried out in animal models. It is worth mentioning that due to the complex etiopathogenesis of ischemic stroke and dynamic nature of processes occurring in its different types, the analysis of diagnostic applicability of particular biomarkers requires thorough understanding of 


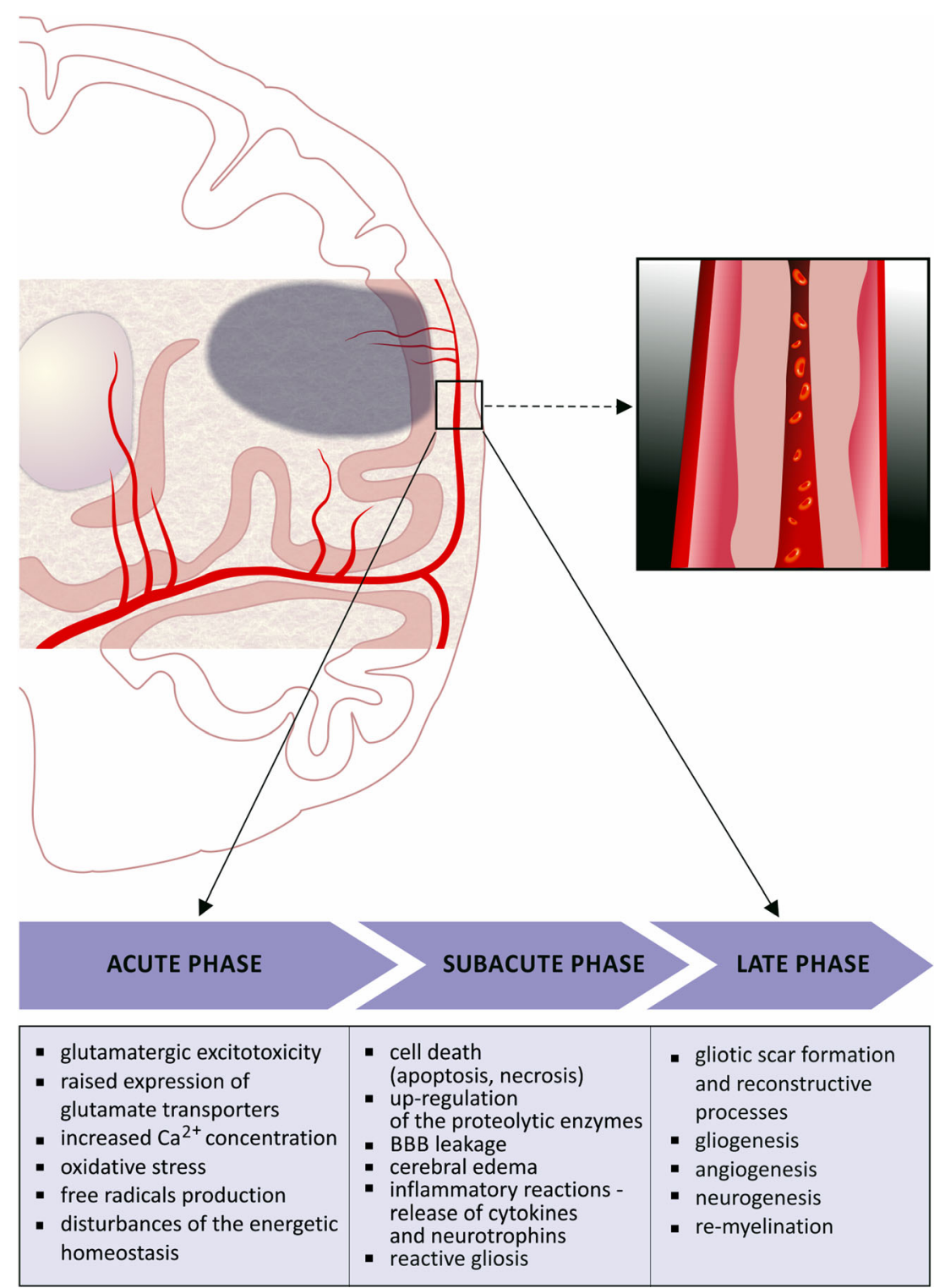

Fig. 1 Summary of pathophysiological processes developing in the course of ischemic stroke. The consequences of ischemic stroke result from processes beginning in a strictly defined time sequence. A decrease in cerebral blood flow results in reduction of oxygen and glucose delivered to the brain tissue. This initiates a cascade of biochemical processes ultimately leading to cellular destruction and death. One of the earliest consequences of these processes is change of oxidative glycolysis into less effective anaerobic pathway, followed by decrease in ATP production and raising lactate concentration. This results in decrease in all energy-dependent metabolic processes and dysfunction of the ion pumps leading to changes of ion concentrations (i.e., decrease in $\mathrm{K}^{+}$ intracellular levels and increase in $\mathrm{Cl}^{-}, \mathrm{Na}^{+}$, and $\mathrm{Ca}^{2+}$ levels). This in turn contributes to influx of water and development of brain swelling. Depolarization of neuronal cell membranes leads to release of excessive amounts of glutamate and triggering glutamatergic excitotoxicity. Stimulating effect of glutamate, by changing $\mathrm{Ca}^{2+}$ concentration and activation of enzymes (e.g., proteases, lipases, phosphatases, and endonucleases), leads to further cell destruction. This is accompanied by the activation of oxidative stress along with an increase in production of free oxygen and nitrogen radicals. A further consequence of these processes is triggering of inflammatory response and release of proinflammatory cytokines and chemokines which destructive action affects all elements of neurovascular unit (NVU). In cerebral vessels, increase in permeability of
BBB and damage to the endothelial cells occur, accompanied by upregulation of thrombotic mechanisms. These processes are accompanied by apoptotic and necrotic cell death, which are dependent on the length of cerebral blood flow reduction, extent of the energetic metabolism disturbances, and localization of the cells (within infarct core or penumbra). Decrease in the cerebral blood flow and reduced availability of oxygen and glucose initiate the acute phase (up to $24 \mathrm{~h}$ from ischemia onset) processes in the course of ischemic stroke, i.e., glutamatergic excitotoxicity, increase in $\mathrm{Ca}^{2+}$ levels, and anaerobic glycolysis, leading to reduced efficiency of the energetic metabolism. The subacute phase (up to 7 days from ischemia onset) is characterized by occurrence of various forms of cell death, the blood-brain barrier (BBB) disintegration and leakage, as well as, initiation of the inflammatory response followed by release of mediators exacerbating the effects of primary damage. In contrast to the earlier phases, during the late phase (starting one week from ischemia onset), the initiated processes lead to limiting of deleterious effects of the cerebral blood flow reduction through development of reactive gliosis and gliotic scar, which enables demarcation of the necrotic infarct core from the surrounding intact tissue. At this phase, the reparative processes resulting from cell proliferation and differentiation dominate, what is reflected in intensive reconstruction of the cellular populations, angiogenesis and re-myelination. 


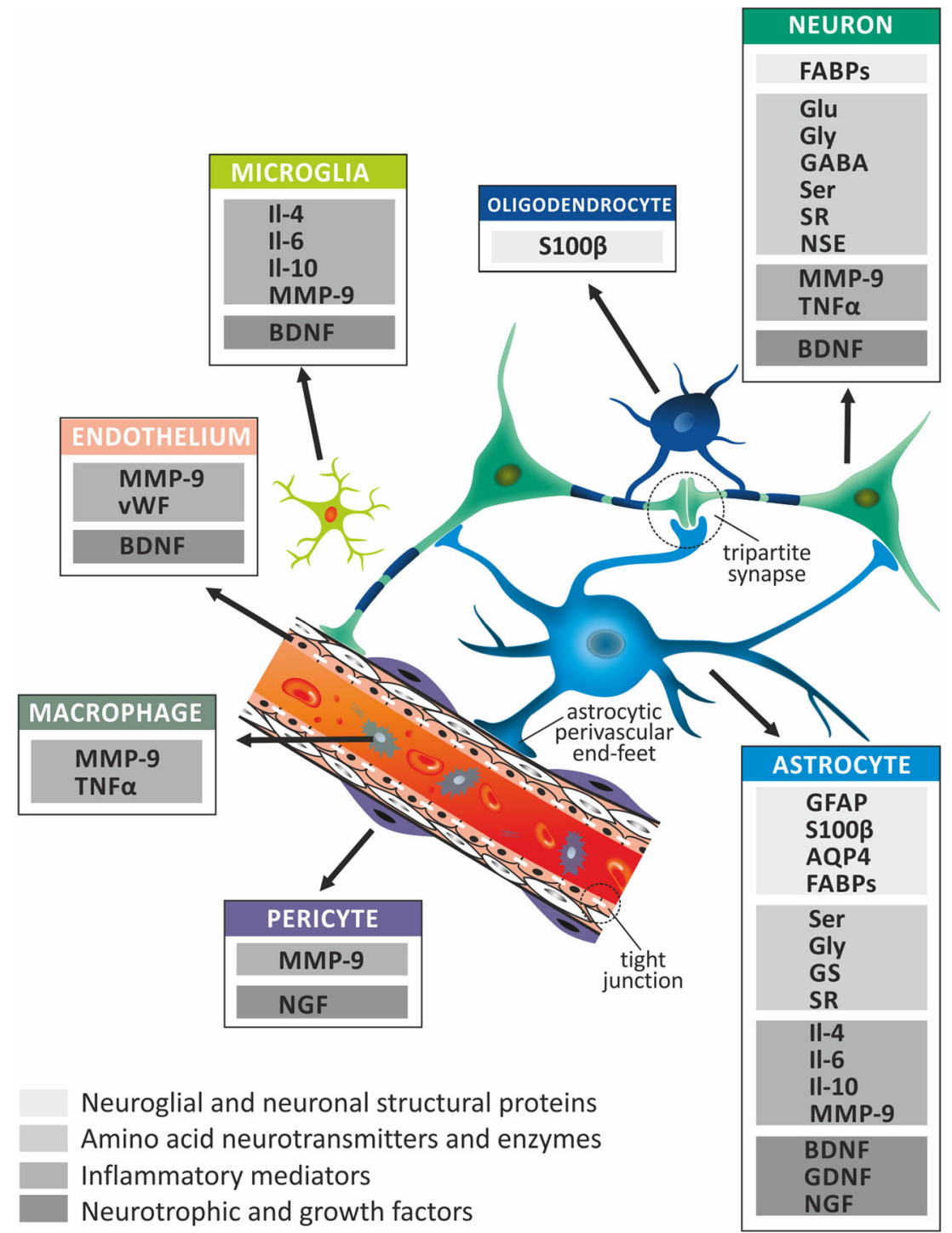

Fig. 2 The neurovascular unit (NVU) as a source of ischemic stroke biomarkers. The NVU concept has been proved useful for analysis of spatial and functional relationships among constituents of brain tissue. An important role of NVU is attributed to its characteristic morphological structures, such as tripartite synapses, astrocytic perivascular end-feet and vascular tight junctions. In accordance with the NVU concept, ischemic stroke biomarkers can be categorized as the representatives of either individual cell type or its several components. In addition, this concept enables division of ischemic stroke biomarkers into groups characterized by similar structure and functions representing the following categories: (1) neuroglial and neuronal structural proteins, (2) amino acid neurotransmitters and enzymes, (3) inflammatory mediators, and (4) neurotrophic and growth factors. While planning the research on the new ischemic stroke biomarkers, it is important to take into account that various components of NVU play different roles in the ischemic

their role and knowledge about the changes in their expression in each type and phase of ischemic infarct. In the case of many potential biomarkers, the results of such studies are not available yet. Moreover, while choosing the potential markers for further clinical trials, the results of studies obtained exclusively based on in vitro or in vivo protocols, metabolic processes (e.g., oxidative and anaerobic glycolysis); signaling pathways (e.g., glutamate-glutamine shuttle, $\mathrm{Ca}^{2+}$ ion- and purines-based signaling) reveal different sensitivity to decreased cerebral blood perfusion, as well as, reveal different proliferation potential. Consequently, the NVU concept is useful for assessment of brain tissue damage, which is reflected in concentration changes of various NVUderived biomarkers that translocate from the brain to blood and CSF. AQP4, aquaporin-4; BDNF, brain-derived neurotrophic factor; FABPs, fatty acid-binding proteins; GABA, $\gamma$-aminobutyric acid; GDNF, glial cell line-derived neurotrophic factor; GFAP, glial fibrillary acidic protein; Glu, glutamate; Gly, glycine; GS, glutamine synthetase; Il-4, interleukin4; Il-6, interleukin-6; Il-10, interleukin-10; MMP-9, matrix metalloproteinase-9; NGF, nerve growth factor; NSE, neuron-specific enolase; S100 $\beta$, S100beta protein; Ser, serine; SR, serine racemase; $\mathrm{TNF} \alpha$, tumor necrosis factor $\alpha$; vWF, von Willebrand factor

carried out on the representatives of single species of laboratory animals, should be treated with caution, as it is highly probable to expect significant interspecies differences in regulatory mechanisms, as well as differences in expression of particular markers resulting from the evolutionary and phylogenetic reasons [130]. 
Table 1 Ischemic stroke biomarkers, summary of function, and diagnostic value

\begin{tabular}{|c|c|c|c|c|}
\hline Marker & & Localization & Function and diagnostic significance & References \\
\hline \multicolumn{5}{|c|}{ Neuroglial and neuronal structural proteins } \\
\hline $\begin{array}{l}\text { Glial fibrillary acidic } \\
\text { protein }\end{array}$ & GFAP & Astrocytes & $\begin{array}{l}\text { Marker of cellular integrity and reactive gliosis, upregulated } \\
\text { in ischemic and hemorrhagic stroke and also in traumatic } \\
\text { brain injury; useful for differentiating between ischemic and } \\
\text { hemorrhagic stroke; correlation reported between GFAP } \\
\text { concentration in CSF and neurological status }\end{array}$ & {$[29,35-39]$} \\
\hline $\mathrm{S} 100 \beta$ protein & $\mathrm{S} 100 \beta$ & $\begin{array}{l}\text { Astrocytes, oligodendrocytes } \\
\text { and Schwann cells }\end{array}$ & $\begin{array}{l}\text { Marker of neuroprotective or neurotoxic function depending } \\
\text { on its serum concentration, supports neurogenesis and } \\
\text { neuronal differentiation, in higher concentrations promotes } \\
\text { necrotic and apoptotic cell death; sensitive biomarker of } \\
\text { ischemic stroke, valuable for assessment of stroke malignant } \\
\text { and hemorrhagic transformation and for stroke mimics } \\
\text { exclusion; correlation reported between S100ß serum and } \\
\text { CSF level and infarct volume }\end{array}$ & {$[38,40-45]$} \\
\hline Aquaporin-4 & AQP4 & $\begin{array}{l}\text { Astrocytic perivascular } \\
\text { end-foot }\end{array}$ & $\begin{array}{l}\text { AQP4 facilitates astrocytic swelling in cytotoxic edema and } \\
\text { enhances water clearance in vasogenic edema; revealed } \\
\text { association between AQP4 expression and intensity of brain } \\
\text { edema studied in MRI and PET; potential biomarker of brain } \\
\text { edema and status of physiological brain barriers }\end{array}$ & {$[46-49]$} \\
\hline $\begin{array}{l}\text { Fatty acid-binding } \\
\text { proteins }\end{array}$ & FABPs & Neurons and neuroglia & $\begin{array}{l}\text { Proteins responsible for maintaining of appropriate serum } \\
\text { concentration of the long-chain fatty acids; potentially } \\
\text { valuable for assessment of infarct volume, prediction of } \\
\text { neurological deficits and differentiation among types of is- } \\
\text { chemic infarcts }\end{array}$ & {$[50-53]$} \\
\hline \multicolumn{5}{|c|}{ Amino acid neurotransmitters and enzymes } \\
\hline Glutamate & Glu & Neurons, astrocytes & $\begin{array}{l}\text { Widely distributed excitatory neurotransmitter; valuable for } \\
\text { assessment of specific types of stroke; changes of its } \\
\text { concentration in blood serum and CSF correlate with } \\
\text { progressive or stable dynamics of ischemic stroke, } \\
\text { changes of neurological status, early deterioration } \\
\text { and infarct volume }\end{array}$ & {$[54-56]$} \\
\hline Glycine & Gly & Neurons, astrocytes & $\begin{array}{l}\text { Amino acid neurotransmitter regulating neuronal activity; } \\
\text { changes of its serum or CSF concentration can be related } \\
\text { with development of functional deficits or excitatory } \\
\text { symptoms; diagnostic value of Gly for prediction of } \\
\text { outcome in different types of stroke and differentiation } \\
\text { ischemic stroke from negative control requires further studies }\end{array}$ & {$[54,55,57-60]$} \\
\hline $\begin{array}{l}\text { Gamma-aminobutyric } \\
\text { acid }\end{array}$ & GABA & Neurons, astrocytes & $\begin{array}{l}\text { Most widely distributed inhibitory amino acid } \\
\text { neurotransmitter; dysregulation results in motor, memory } \\
\text { and cognitive disorders; association between GABA } \\
\text { concentration changes and progressive stroke or } \\
\text { neurological deterioration especially in lacunar infarcts }\end{array}$ & [61-69] \\
\hline Serine & Ser & Neurons, astrocytes & $\begin{array}{l}\text { Physiological function of Ser relays on co-activation } \\
\text { of the NMDA receptors; based on its transient increase } \\
\text { after reversible cerebral ischemia, its value as an indicator of } \\
\text { threatening glutamatergic excitotoxicity can be considered }\end{array}$ & {$[70,71]$} \\
\hline Glutamine synthetase & GS & Astrocytes & $\begin{array}{l}\text { Enzyme responsible for maintaining of glutamate-glutamine } \\
\text { balance, reveals increased expression after transient cerebral } \\
\text { ischemia; its diagnostic value in assessment of threatening } \\
\text { glutamatergic excitotoxicity and size of brain tissue damage } \\
\text { can be considered }\end{array}$ & {$[72-75]$} \\
\hline Serine racemase & SR & Neurons, astrocytes & $\begin{array}{l}\text { Enzyme isomerizing L-serine into D-serine; diagnostic } \\
\text { significance as an indirect marker of glutamatergic } \\
\text { excitotoxicity and brain tissue damage can be considered }\end{array}$ & {$[71,76]$} \\
\hline $\begin{array}{l}\text { Neuron-specific } \\
\text { enolase }\end{array}$ & NSE & Neurons & $\begin{array}{l}\text { Glycolytic enzyme, changing expression in acute phase of } \\
\text { ischemic stroke; correlation reported between the NSE } \\
\text { serum level and ischemic infarct volume; indicator of } \\
\text { ischemic infarct hemorrhagic transformation; predictor of } \\
\text { outcome after complications resulting from diagnostic and } \\
\text { therapeutic procedures }\end{array}$ & [77-82] \\
\hline
\end{tabular}


Table 1 (continued)

\begin{tabular}{|c|c|c|c|c|}
\hline Marker & & Localization & Function and diagnostic significance & References \\
\hline Interleukin-6 & Il-6 & Astrocytes, microglia & $\begin{array}{l}\text { Proinflammatory cytokine regulating release of inflammatory } \\
\text { mediators, apoptosis and BBB integrity; association of its } \\
\text { concentration with increase of ischemic infarct volume; } \\
\text { predictor of risk estimation and outcome prognosis in } \\
\text { progressive stroke, TIA and lacunar stroke }\end{array}$ & {$[82-88]$} \\
\hline $\begin{array}{l}\text { Matrix } \\
\text { metalloproteinase-9 }\end{array}$ & MMP-9 & $\begin{array}{l}\text { Neurons, astrocytes, microglia, } \\
\text { macrophages, pericytes and } \\
\text { endothelial cells }\end{array}$ & $\begin{array}{l}\text { Collagenase responsible for breakdown of extracellular matrix; } \\
\text { its increased level in acute ischemic stroke is associated with } \\
\text { higher risk of neurological deficits, infarct hemorrhagic } \\
\text { transformation and mortality; positive role of MMP-9 in } \\
\text { stroke recovery is discussed }\end{array}$ & [89-96] \\
\hline $\begin{array}{l}\text { Tumor necrosis factor } \\
\alpha\end{array}$ & $\mathrm{TNF} \alpha$ & Macrophages, neurons & $\begin{array}{l}\text { Factor enhancing astrocytic and microglial inflammatory response } \\
\text { in ischemia-reperfusion injury, also involved in regulation of } \\
\text { cell death and glutamatergic excitotoxicity; valuable in } \\
\text { assessment of stroke with accompanying metabolic disorders; } \\
\text { diagnostic value for prediction of neurological status after } \\
\text { hypoxia-ischemia injury in newborns and carotid artery stenting }\end{array}$ & {$[97-104]$} \\
\hline von Willebrand factor & vWF & $\begin{array}{l}\text { Endothelial cells, } \\
\text { megakaryocytes }\end{array}$ & $\begin{array}{l}\text { Glycoprotein involved in platelet adhesion and aggregation, } \\
\text { influences inflammatory response through regulation of } \\
\text { cytokine release; biomarker of diagnostic value in acute } \\
\text { phase of all types of ischemic stroke, also related with } \\
\text { increased risk of the first ischemic stroke, poor neurological } \\
\text { outcome and hemorrhagic transformation of ischemic infarct }\end{array}$ & {$[25,105-108]$} \\
\hline Interleukin-4 & Il-4 & Astrocytes, microglia & $\begin{array}{l}\text { Cytokine of anti-inflammatory function, contributing to re- } \\
\text { duction of acute ischemic damage and infarct volume; reg- } \\
\text { ulates expression of anti-inflammatory mediators; consid- } \\
\text { ered potential predictor of neurological status in acute phase } \\
\text { of ischemic stroke }\end{array}$ & {$[109-111]$} \\
\hline Interleukin-10 & Il-10 & Astrocytes, microglia & $\begin{array}{l}\text { Anti-inflammatory and neuroprotective cytokine, inhibits } \\
\text { neuronal apoptosis; considered predictor of neurological } \\
\text { status of patients with small-vessel disease }\end{array}$ & {$[88,112-114]$} \\
\hline \multicolumn{5}{|c|}{ Neurotrophic and growth factors } \\
\hline $\begin{array}{l}\text { Brain-derived } \\
\text { neurotrophic factor }\end{array}$ & $\mathrm{BDNF}$ & $\begin{array}{l}\text { Neurons, astrocytes, microglia, } \\
\text { ependymal and endothelial } \\
\text { cells }\end{array}$ & $\begin{array}{l}\text { Modulator of signaling pathways and cytokines release; } \\
\text { prognostic significance for evaluation of functional outcome } \\
\text { after ischemic stroke and impending post-stroke depression } \\
\text { or cognitive impairment is discussed }\end{array}$ & {$[115-120]$} \\
\hline $\begin{array}{l}\text { Glial cell line-derived } \\
\text { neurotrophic factor }\end{array}$ & GDNF & Astrocytes & $\begin{array}{l}\text { Modulator of inflammatory response and astrogliosis, } \\
\text { improving post-stroke recovery; alleviates learning and } \\
\text { memory disorders; can be considered a potential biomarker } \\
\text { of neuroprotective processes and BBB status }\end{array}$ & {$[121-125]$} \\
\hline Nerve growth factor & NGF & Astrocytes, pericytes & $\begin{array}{l}\text { Inhibitor of apoptosis, enhancing cognitive and memory } \\
\text { processes after transient cerebral ischemia in vivo; } \\
\text { assessment of clinical diagnostic value is inconclusive; } \\
\text { further studies are necessary to determine significance of this } \\
\text { biomarker in different types of stroke }\end{array}$ & {$[126-129]$} \\
\hline
\end{tabular}

\section{Neuroglial and Neuronal Structural Proteins}

\section{Glial Fibrillary Acidic Protein}

GFAP is a valuable marker of cellular integrity. Changes in expression of this astrocytic cytoskeleton protein are strongly dependent on the intensity of reactive gliosis [29, 35]. Upregulation of GFAP has been found not only in the course of ischemic but also in the hemorrhagic stroke. In the latter, the increase in expression is even higher than that in the ischemic infarct $[36,37]$. In the course of the hemorrhagic stroke, its highest serum level occurs between 2 and $6 \mathrm{~h}$
[36], whereas after ischemic stroke onset the increase in serum concentration raises after $24 \mathrm{~h}$ and reaches maximal level between the second and the third day [131]. However, correlation between the size of lesion and GFAP serum concentration does exist in the case of hemorrhagic stroke and not for the ischemic stroke, but only after $2 \mathrm{~h}$ from its onset. This can be explained by initially small volume of lesioned tissue, which increases with the time lapse [132]. Therefore, in the time window between 2 and $6 \mathrm{~h}$ after stroke onset, GFAP could be considered useful for differentiation between hemorrhagic and ischemic stroke. However, during the first $2 \mathrm{~h}$, GFAP sensitivity for detecting hemorrhagic stroke is low, which 
makes this marker useless in diagnosis of the earliest phase of this pathology. Interestingly, the difference in GFAP expression between hemorrhagic and ischemic stroke has not been confirmed in Chinese cohort study, which provides evidence for existing ethnic differences that should be taken into consideration by analyzing different population studies [133]. There is also evidence indicating a correlation between GFAP concentration in CSF and the National Institutes of Health Stroke Scale (NIHSS) score in patients during acute phase of stroke, and a correlation between this marker level and the infarct volume, as well as modified Rankin Scale (mRS) score after three months from the stroke onset [38].

In addition to being useful in diagnosing hemorrhagic stroke, GFAP could have some value in diagnosing early phase of traumatic brain injury [39]. Due to its high sensitivity (56-89\%) and specificity (100\%), it is a useful indicator of traumatic brain injury, helpful in assessing the patient's early condition after injury or choosing further diagnostic methods and therapy. However, it should be taken into account that its concentration decreases after $6 \mathrm{~h}$ [132].

Overall, GFAP cannot be considered a specific marker of hemorrhagic or ischemic stroke during the very early phase $(0-2 \mathrm{~h})$. The difference in the dynamics of its expression in the early stages (between 2 and $6 \mathrm{~h}$ ) of the course of both forms of stroke can, however, shed light on the etiology (hemorrhagic or ischemic) and thus, in combination with the data from the patient's history and the results of the neurological examination and radiological tests (if available), can facilitate differentiating diagnosis. Despite the increasing availability of neuroimaging tests, there is still a fairly large group of patients, in whom these examinations were not performed in the early stages of stroke or clinical evaluation in pre-hospital settings was undertaken by a non-specialist. In such cases, an assessment of GFAP level and dynamics of its changes may be useful in diagnostic process and considering most appropriate therapy. The characteristic difference in dynamics of its concentration changes may provide some help in differentiating diagnosis in the absence of precise data on the time point of stroke onset. In addition, there are premises indicating GFAP value in determining outcome prognosis and neurological status of stroke patients. In summary, GFAP cannot be considered a characteristic marker of only one type of stroke and is also activated in the course of traumatic brain injury. However, different dynamics of its concentration changes in the blood serum, association with the size of tissue damage, and patients' outcome indicate the diagnostic value. Determining possibilities of its clinical application requires further studies.

\section{S100 Beta Protein}

The S100 $\beta$ protein, a representative of the S100-calmodulintroponin cytoplasmic proteins family, is present in astrocytes, oligodendrocytes, and Schwann cells. The S100 $\beta$ protein reveals neuroprotective or neurotoxic function, depending on its concentration level $[40,41]$. In the nanomolar concentrations, it supports neurogenesis and neuronal differentiation [134]. This role of $S 100 \beta$ protein is associated with the regenerative processes occurring after stroke (e.g., in hippocampus), as well as with postischemic neuroplasticity. These processes can be responsible for improvement of cognitive and memory functions after ischemic stroke [40, 134]. In higher concentrations, the $S 100 \beta$ protein stimulates the release of nitric oxide (NO) and NF- $\mathrm{KB}$ and promotes both necrotic and apoptotic cell death $[42,135,136]$. Changes of the S100 $\beta$ protein expression are to the lesser degree dependent on the intensity of reactive gliosis, compared to GFAP. The correlation between the $\mathrm{S} 100 \beta$ protein serum level and the infarct volume has been revealed between the first and the fourth day of ischemia [137-139]. The $S 100 \beta$ protein leakage from astrocytes starts after $4 \mathrm{~h}$ from the ischemia onset and depends from depth of the cerebral blood flow reduction and tissue destruction. An early increase of the $\mathrm{S} 100 \beta$ protein serum levels has been reported to be associated with the malignant form of ischemic stroke, characterized by occurrence of clinical signs of cerebral herniation, loss of brain stem reflexes, and death within 7 days after symptom onset after proximal MCA occlusion [43]. A single measurement of $\mathrm{S} 100 \beta$ protein in serum between 12 and $24 \mathrm{~h}$ after ischemia onset has a predictive value and can be a valuable confirmation of the results assessed on the basis of neurological examination and neuroradiological studies. In the course of cerebral ischemic stroke and TIA, an increase in concentration of $\mathrm{S} 100 \beta$ protein in CSF was detected within about $9 \mathrm{~h}$ from the stroke symptoms onset [38]. Aurell et al. observed an increase in S100 $\beta$ in CSF within $48 \mathrm{~h}$ from stroke symptoms onset. This increase was transiently sustained for one week and decreased subsequently [44]. Additionally, in this study, a significant correlation was found between the CSF S100 $\beta$ protein concentration and the infarct size. The CSF S100 $\beta$ levels positively correlate with stroke severity, assessed with the NIHSS score on admission, also with an infarct volume, and with patients' outcome according to the mRS score after three months from the ischemic infarct onset [38]. S100ß protein levels in CSF are differentiated in various types of stroke, being higher in cardioembolic stroke, compared to the small-vessel disease, and they correlate with an infarct volume [45].

In summary, the unique significance of $\mathrm{S} 100 \beta$ protein as a potential biomarker of ischemic stroke results from the fact that it undergoes early upregulation in the course of brain tissue damage (as in the case of malignant stroke) and is a good predictor of dynamically occurring destructive processes. Depending on the extent of cerebral blood flow reduction, gradual transition of penumbra into the ischemic core can occur very dynamically, within the first $24 \mathrm{~h}$ from ischemia onset. In a significant proportion of cases, the ischemic "at risk 
zone" is not visible on CT imaging, even up to $24-48 \mathrm{~h}$ from its onset [139]. In these cases, an increase in concentration of S100 $\beta$ protein may serve as an early warning signal before it becomes visible in the $\mathrm{CT}$ image (if available) in the early phase of stroke. Hence, this biomarker can be helpful for predicting development of malignant stroke, increase of infarct volume, or exclusion of stroke mimics.

\section{Aquaporin-4}

AQP4 is a member of the water-channel proteins family, expressed in the end-foot of astrocytes, which surround capillary vessels, ventricular walls or subarachnoid space [140]. AQP4 reveals different effects upon brain tissue, depending on the prevailing type of brain edema. It facilitates astrocytic swelling in the course of cytotoxic edema and enhances extracellular water clearance in vasogenic edema [46, 47]. AQP4 expression pattern in the course of brain ischemia may be different [141]. It can be either up- or downregulated, as a result of the extent of astrocytic damage, reaching critical threshold level. In both cases, changes in AQP4 level are associated with blood vessel wall damage, BBB disintegration, and its increased permeability. There is evidence indicating that AQP4 deficit results in tight junctions opening and perivascular astrocytic end-feet swallowing, which promote development of brain edema [142]. AQP4 also contributes to regulation of regional cerebral blood flow in capillaries [143]. Inhibition of AQP4 expression significantly increases regional cerebral blood flow [144]. All these studies prove AQP4 involvement in development of the malignant brain edema or hemorrhagic transformation of ischemic infarct and justify its value as a potential biomarker. The increase of the AQP4 expression after transient ischemic stroke has been observed between the first and third day of reperfusion [145]. However, the direct assessment of the AQP4 content in the blood serum has not been proved as useful for stroke diagnosis. Importantly, the changes in AQP4 expression and concentration level during brain edema correlate with the MRI results of diffusion-weighted imaging (DWI) and T2-weighted imaging (T2WI) studies [48].

Badaut et al. [28] showed in a rat pup stroke model that upregulation of AQP4 protein expression on astrocytic endfeet (studied with immunohistochemistry) correlated with edema formation assessed with the high-field MRI. This observation should be taken into account when considering diagnostic application of AQP4 in clinical practice. In particular, this correlation can provide some valuable data concerning evolution of the ischemic area and development of potential complications, such as malignant stroke or hemorrhagic transformation of the lesioned region. Similarly, the PET imaging studies have been claimed to reveal an association with distribution and concentration changes of AQP4 in different brain areas, in particular, in the subpial or perivascular regions and in the choroid plexus [49]. Although at present, PET is not a standard method used to assess the content of AQP4 in the CNS. However, it could provide valuable information based on AQP4 function in the course of ischemic process and its uneven distribution in the brain. This could be of importance when considering AQP4 as diagnostic marker or potential therapeutic target [49].

The abovementioned data are of important practical value for elaboration of future diagnostic protocols, based on the distribution of ischemic biomarkers and results of functional neuroradiological imaging studies. This approach, based on evaluation of biomarkers' concentration and distribution, together with the results of neuroradiological studies, could also enable assessment of status of physiological brain barriers (e.g., BBB, blood/CSF barrier, or brain/CSF barrier) in the course of ischemic stroke.

\section{Fatty Acid-Binding proteins}

Fatty acid-binding proteins (FABPs) represent a family of cytoplasmic proteins, responsible for maintaining an appropriate serum concentration of the long-chain fatty acids and expression of genes regulating cellular growth and differentiation $[50,146]$. Two of nine proteins from this family, namely H-FABP and B-FABP (detected in neurons and neuroglia, respectively), are of some importance for the cerebral stroke diagnosis $[51,52]$. Studies have shown a correlation between a H-FABP blood serum concentration and size of the ischemic infarct evaluated by $\mathrm{CT}$ studies, especially when the infarct volume had exceeded $150 \mathrm{ml}$ [50]. Moreover, an association has been found between $\mathrm{H}-$ FABP serum levels and severity of neurological deficits, as well as functional outcome assessed with the NIHSS and mRS. The highest serum concentrations of another fatty acid-binding protein, B-FABP, were found in lacunar and small subcortical infarcts of $1-50 \mathrm{ml}$ volume. In contrast to H-FABP, no correlation was found between B-FABP serum levels and neurological deficits in stroke patients. Lack of correlation between NIHSS or mRS and B-FABP level may result from minor damage to the nervous tissue. Moreover, distribution of B-FABP predominantly in neuroglial cells (in contrast to H-FABP found mainly in neurons) can explain the different nature of brain tissue lesion, associated to a greater extent with neuroglial than neuronal damage. Consequently, this may be responsible for less pronounced neurological deficits and the lack of correlation between the B-FABP level and patient's clinical condition, assessed by NIHSS and mRS scores.

The advantage of using both FABPs as potential stroke biomarkers is related with early increase of their serum concentrations during stroke, which occurs already within 2 to $3 \mathrm{~h}$ after ischemia and remains elevated up to $120 \mathrm{~h}$. The disadvantage is concerned with their relatively low specificity, 
whereas increase in H-FABP concentration has also been observed in the hemorrhagic stroke [53]. The serum levels of both these markers can be indicators of stroke damage size. Indeed, simultaneous assessment of both biomarkers provides greater benefit allowing to draw conclusions not only as to size of the damaged area, correlation with functional deficit, and prognosis (high level of H-FABP), but also as to the type of stroke (e.g., lacunar or small-vessel disease, when high level of B-FABP). In the early phase of both ischemic and hemorrhagic stroke, small size of damage may be the reason why changes in both biomarkers' concentration are not specific enough to allow for clear differentiation between these two forms. While low level of H-FABP and high level of BFABP do not allow for differentiation between hemorrhagic and ischemic stroke, some other information could be obtained based on changes in these biomarkers such as the time point of stroke onset (upregulation even within 2-3 h after stroke onset), nature of tissue damage (rather neuroglial than neuronal lesion), size of lesion, and pathophysiological type of stroke (more likely lacunar than large ischemic infarct). In such a case, diagnosis may be supported by assessment of the other markers used in the diagnostic panel, accompanied by neurological status assessment, and results of neuroradiological examinations.

Reassuming, perspectives of diagnostic application of FABPs as ischemic stroke biomarkers are promising, although require further investigation. Their advantage is in principle concerned with rapid increase of serum concentration and multifunctional value, enabling indirect assessment of the volume of ischemic lesion, severity of neurological deficits, and differentiation among types of ischemic stroke.

\section{Amino Acid Neurotransmitters and Enzymes}

The results of numerous studies indicate changes in concentration of both excitatory and inhibitory amino acid neurotransmitters, such as glutamate (Glu) and serine (Ser) or $\gamma$ aminobutyric acid (GABA) and glycine (Gly), respectively, in the course of ischemic stroke. These changes may be a good indicator of the depth of neuronal and neuroglial dysfunction. They may also correlate with the severity of neurological deficits, of both focal character (e.g., hemiparesis, aphasia, or visual deficits) and general nature (e.g., consciousness disturbances or memory and cognitive disorders), depending on localization of the lesioned area. However, dynamic changes in concentration of neurotransmitters, in the course of various types of ischemic stroke, are poorly understood. Further studies on these processes will provide important information concerning dysfunction of particular brain structures affected by ischemia. Another group of potential biomarkers, deriving from the NVU, is represented by enzymes responsible for synthetizing of neurotransmitters and metabolites significant for diagnosis of the ischemic stroke. Among these, one could encounter glutamine synthetase (GS), serine racemase (SR), and neuron-specific enolase (NSE). Their potential role as stroke biomarkers is presented in the following paragraphs.

\section{Glutamate}

In ischemic stroke, an increase in Glu concentration in both blood plasma and CSF was observed. Due to the easy passage through the cerebral functional barriers, these changes were positively correlated, which implies diagnostic value of Glu concentration measurement in both physiological fluids [54, 55]. A progression of neurological deficits and early neurological deterioration, within $72 \mathrm{~h}$ in stroke patients, was observed accompanied by increased concentrations of Glu in both of them.

There is well-documented evidence showing characteristic difference in dynamics of Glu level changes between patients with stable and progressive ischemic stroke $[54,56]$. While in the former there is only a slight Glu increase terminating within $6 \mathrm{~h}$, in the latter, Glu concentration increases considerably and remains elevated for at least $24 \mathrm{~h}$. This has been also observed in patients with a progressive brain swelling diagnosed in CT examination. Glu concentrations exceeding $200 \mu \mathrm{mol} / \mathrm{l}$ in blood plasma and $8.2 \mu \mathrm{mol} / 1$ in CSF are associated with progression of neurological deficit within $48 \mathrm{~h}$. Diagnostic value of Glu concentration assessment in blood plasma and in CSF may also result from correlation between its content and infarct volume. This can indicate the increased risk of poor prognosis in patients with high Glu levels. Reassuming, further studies on diagnostic application of Glu level assessment seem very promising. They should be continued concentrating among others on evaluation of Glu concentration changes in different types of ischemic stroke, as well as on relationship between Glu levels and dynamics of neurological deficit changes.

\section{Glycine}

It has been shown that Gly concentration in blood plasma and CSF increases in stroke patients, correlating with progression of neurological deficits $[54,55]$. As a neurotransmitter present at relatively high concentration in numerous CNS structures, Gly is involved in regulation of neuronal activity in forebrain, brain stem, and spinal cord [57]. The inhibitory action of Gly observed in physiological conditions in different brain areas can be disturbed by ischemia. Increase or decrease of Gly concentration can result in appearance of neurological symptoms in the form of functional deficits or excitation, respectively. In the first case, it can augment motor or sensory deficits [58, 147]; in the second, it can promote conditions initiating epileptic seizures or muscle tone disorders [59]. Some evidence indicates that plasma and CSF concentrations of Gly are higher in patients with progressive ischemic stroke, 
compared to those with its stabile variant, as well as, that their increased concentrations (plasma Gly > $223 \mu \mathrm{mol} / \mathrm{l}$; CSF Gly $>126 \mu \mathrm{mol} / \mathrm{l}$ ) are present in patients with progression of neurological deficits [54, 55]. Results of a recent study show that Gly level assessment can be useful for differentiating patients with ischemic stroke from the control group [60]. Reassuming, all these data suggest that Gly could be a useful biomarker, included in new stroke diagnostic panels, aimed at differentiating ischemic stroke from negative control and differentiating its stabile variant from progressive one.

\section{Y-Aminobutyric Acid}

Concentration of this inhibitory neurotransmitter also reveals characteristic changes in the course of different types of ischemic stroke. Considering the widespread distribution of GABA in cerebral structures, in particular, in areas related to motor function, such as frontal cortex or basal ganglia (e.g., striatum, globus pallidus, subthalamic nucleus and substantia nigra), it can be expected that dysregulation of GABA-ergic neurotransmission, resulting from ischemia, may be responsible for enhancing of disorders, such as paresis, muscular tone dysregulation, or involuntary movements [61]. It can be also responsible for initiation of the epileptic activity [62]. Other brain areas in which GABA-ergic transmission disorders can bring about characteristic dysfunctions are limbic structures, such as hippocampus, amygdala, or prefrontal cortex. Disturbance of the balance between inhibitory and excitatory neurotransmission in these areas can lead to increasing cognitive and memory deficits, pathological emotional disorders (e.g., anxiety), or improper behavioral reactions [63-65]. The relationship has been demonstrated between GABA content and neurological deterioration in the early phase of ischemic stroke [66]. The progressive character of ischemic stroke causes a greater decrease of GABA concentration than in the case of a stable stroke. This can have a predictive value for evaluation of neurological status. Changes in the GABA content have been observed within $24 \mathrm{~h}$ after transient ischemia onset $[67,68]$. In ischemic stroke, the initial increase in GABA concentration is followed by subsequent inhibition of GABA synthesis, leading to GABA-ergic neurotransmission dysfunction, persisting even for the next 3 months [148]. This could explain the observations of some other authors that serum concentration of GABA has not been proved useful as prognostic factor for prediction of ischemic stroke outcome when assessed early after symptoms' onset [149]. The reduction of tonic GABA-ergic inhibition, especially in the early postischemic period, apart from glutamatergic excitotoxicity, may enhance disturbances of synaptic plasticity. However, subsequently occurring increase in GABA content, through limiting damage, can be encountered among the neuroprotective processes [150]. Furthermore, increased tonic GABArelated inhibition, mediated presumably by GABA A receptors, might lead to improved motor function after ischemic stroke [151]. The correlation between concentration of GABA in blood plasma and CSF is poor [152]. This can be explained by the diversity of mechanisms associated with GABA transition through the physiological barriers in the brain after the onset of ischemia. The reduction in the inhibitory effect of GABA during ischemia is not only a consequence of changes in concentration of neurotransmitter itself, but also result of the response induced by GABAergic receptors [153]. During ischemia, the expression of GABA A and GABA B receptors is reduced and their endocytosis is initiated [154]. This weakens the inhibitory GABA-ergic response, thus enhancing the effect of glutamatergic excitotoxicity [153, 155]. On the other hand, if during ischemia the GABA concentration is retained on the higher level in certain brain areas, simultaneous stimulation of GABA A and GABA B receptors results in neuroprotective effect [156]. Regulation of GABAergic receptors' trafficking, their surface expression and recycling, modulate the strength of GABA-ergic synaptic inhibition [157]. GABA-ergic neurotransmission disorders affect the balance between excitation and inhibition of neurons in the area of damage [158]. The large body of evidence indicates reciprocally related changes in GABA and Glu content in the course of ischemia. This could be due to the interrelated biochemical transformation pathways of both these amino acid neurotransmitters, approximately the same time period of their release into the ischemic area, and their involvement in regulation of pathophysiological processes occurring in the early phase of ischemia. Changes in concentration of each of them affect the extent of damage to the ischemic tissue [69]. The blood plasma Glu concentration $>200 \mu \mathrm{mol} / \mathrm{l}$ and GABA concentration $<240 \mathrm{nmol} / \mathrm{l}$ can be considered predictors of early neurological deterioration in the course of lacunar infarction [66]. A decrease in GABA content in the plasma, with concomitant increase in Glu level, results in increased Glu/ GABA ratio, which is characteristic for glutamatergic excitotoxicity. Moreover, a Glu/GABA ratio higher than 106 is regarded as a predictor of early neurological deterioration in $85 \%$ of patients with lacunar infarction. Subsequent increase in GABA secretion leading to reduction of this ratio signals lowering of the intensity of damage and promotion of reparative processes [150]. The Glu/GABA ratio can differ between the infarct core and peripherally localized penumbra [159]. Thus, the assessment of Glu/GABA ratio, along with the evolution of changes in the ischemic area observed in neuroradiological studies, may become useful diagnostic and prognostic tool.

In summary, decrease in GABA concentration in the blood plasma could be a predictor of the worse outcome in patients with progressive stroke. Demonstration of the relationship between GABA and Glu concentration changes, localization of the ischemic area, and severity of functional disorders in the course of ischemia can 
provide interesting data supplementing diagnosis and prediction of complications in the course of ischemic stroke.

\section{Serine}

This amino acid co-neurotransmitter and gliotransmitter is widely distributed in the CNS in two isoforms, of which DSer is converted from L-Ser in neurons and astrocytes [160, 161]. Physiological function of D-Ser relays on binding to Gly site and co-activating NMDA receptors, whereas overstimulation can result in glutamatergic excitotoxicity. After transient ischemia, D- and L-Ser blood concentrations transiently increase, reaching their maximal levels at $20 \mathrm{~h}$, which suggests their role as biomarkers of the acute phase of ischemia [70]. Some authors point to potentially neuroprotective effect resulting from reduced D-Ser binding to the NMDA receptor, which has been described in pathological processes related to reduced synthesis of Ser [71]. This results in decreased NO and Glu release and in consequence, in reduced infarct volume. Reassuming, although the role of Ser in various types of ischemic stroke and its different phases has not been extensively studied, dynamic changes in its content, especially in the early phase of ischemia, and the widespread regulation based on NMDA receptors, indicate the importance of assessment of Ser concentration changes. Monitoring of this amino acid levels could have some prognostic value as an indirect indicator of threatening glutamatergic excitotoxicity or neuroprotective processes, depending on its concentration levels.

\section{Glutamine Synthetase}

This glutamine (Gln) synthetizing astrocytic enzyme is responsible for maintaining of $\mathrm{Glu} / \mathrm{Gln}$ balance in physiological conditions [162]. It is sensitive to free oxygen and nitrogen radicals that inactivate it when released during the early phase of ischemia [72, 73]. However, GS activity is rapidly restored, especially after transient ischemia $[73,74]$. The GS immunoreactivity has been reported to be increased within $3 \mathrm{~h}$ of postischemic reperfusion [75]. Due to its involvement in dysregulation of Glu/Gln balance and transient increase in Glu levels, GS is indirectly responsible for destructive effects of Glu excitotoxicity. Hence, GS activity level and concentration assessment during ischemia can predict the deleterious effects of Glu exerted upon infarcted area. This indicates direction of further research on this enzyme, as an indicator of an early neurological deterioration in the course of transient ischemia. Overall, dynamic character of GS activity, its expression changes and involvement in regulation of the Glu/Gln balance, suggest an important role of this enzyme in ischemic stroke and justify further studies.

\section{Serine Racemase}

Function of SR is concerned with isomerizing of L-Ser into DSer [163]. Recent studies have shown that mRNA and protein levels of SR are higher in neurons than in astrocytes [164]. In mouse model of permanent ischemia, the SR mRNA and protein expression decrease between the 6th and 10th day after stroke [76]. The exact explanation of downregulation of SR in subacute phase of ischemia is unknown. It has been speculated that it could be a consequence of transient decrease in its transcription. This is consistent with the D-Ser role in stimulation of NMDA receptors, presumably in the acute phase of brain ischemia, resulting in maximal excitotoxic damage. Hence, the decrease in SR protein and mRNA levels during subacute phase could be related with cellular death, resulting from glutamatergic excitotoxicity. Changes of the SR expression could be taken into account as indirect indicator of glutamatergic excitotoxicity and destructive processes [71]. However, no clinical results confirming the SR diagnostic value are available and additional studies are required to verify its significance as a potential biomarker.

\section{Neuron-Specific Enolase}

NSE is an isoform of glycolytic enzyme, which expression changes in acute phase of ischemic stroke [77]. In this process, the NSE serum levels are higher, compared to the hemorrhagic stroke and positive correlation has been reported between the ischemic infarct area and the NSE serum levels in acute phase of stroke. In contrast, no association has been found between NSE levels and hemorrhagic infarct volume [165]. Dynamic changes of the NSE serum levels in acute ischemic stroke are predictive for its hemorrhagic transformation and BBB disruption [78]. An association has also been found between the NSE serum levels and severity of cerebral venous thrombosis and NSE is regarded as a predictor of clinical outcome in this process [166]. Evaluation of the NSE levels has been recommended as a valuable indicator of poor outcome or death in the course of hypoxic-ischemic brain lesion after cardiac arrest $[79,167]$. Complications occurring after diagnostic and therapeutic procedures are also concerned with changes in the NSE levels. The increase of its serum levels at $48 \mathrm{~h}$ has a predictive value in the course of ischemiareperfusion brain damage after internal carotid endarterectomy [80]. This enzyme could also be useful for diagnosis of the silent cerebral infarcts caused by microemboli in the course of invasive coronary procedures [81]. Finally, an association has been found between the lower NSE concentration and favorable outcome after intravenous thrombolysis [82]. Reassuming, the role of NSE in the course of cerebral stroke is complex. Changes of its concentration are associated with destructive processes affecting brain tissue during cerebral stroke, such as BBB disruption and hemorrhagic 
transformation. Its involvement as potential indicator of complications, which occur during diagnostic and therapeutic procedures, justify the need for further studies on this enzyme.

\section{Inflammatory Mediators}

Another group of potential ischemic stroke markers consists of pro- and anti-inflammatory mediators. Majority of these biomarkers is not characteristic for one cellular subpopulation but rather for all constituents of NVU [168, 169]. The proinflammatory and neurodegenerative mediators are represented by cytokines (interleukin-6; IL-6), enzymes (matrix metalloproteinase-9; MMP-9), neurodegenerative factors (tumor necrosis factor $\alpha$; TNF $\alpha$ ), and hemostatic factors (von Willebrand factor; vWF). Among the anti-inflammatory cytokines could be encountered interleukin-4 (IL-4) and interleukin-10 (IL-10).

\section{Interleukin-6}

IL-6 is a proinflammatory cytokine secreted by microglia or astrocytes, depending on the acute or subacute phase of ischemic stroke, respectively $[170,171]$. This interleukin reveals modulatory effect upon apoptosis, the BBB integrity, and secretion of other inflammatory cytokines [82]. Its serum levels increase in the course of ischemic stroke, and together with the infarct size assessment, this factor can be used as a valuable predictor of stroke prognosis [83, 84]. Elevated concentration of IL- 6 at $6 \mathrm{~h}$ and increased NIHSS score on admission were associated with early deterioration within $48 \mathrm{~h}$ or death. At $72 \mathrm{~h}$ from the ischemic infarct onset, IL-6 concentration correlated with the $\mathrm{S} 100 \beta$ protein levels and size of tissue damage [172]. The IL-6 serum levels changes could also be useful for evaluation of transient ischemic attack (TIA) and silent lacunar infarction. Studies revealed prognostic value of IL-6 for the risk estimation in TIA and first-ever cerebrovascular events $[85,86]$. Some recent studies also have shown higher levels of IL-6 in the course of large-artery stroke, compared to the lacunar stroke [172]. Changes in IL-6 serum concentration are not characteristic exclusively for ischemic infarcts and have been also found in the course of subarachnoid hemorrhage and hemorrhagic stroke [173, 174]. Higher levels of IL6 detected between 3 and 7 days after subarachnoid hemorrhage were associated with delayed ischemic neurological deficits and unfavorable outcome. In hemorrhagic stroke, IL-6 level was increased between days 1 and 4, although the level was lower compared to the ischemic stroke [175]. High levels of IL-6 in the acute phase of hemorrhagic stroke correlated with the severity of the cerebral edema and indicated a poor neurological outcome $[87,88]$. The results of the abovementioned studies indicate that role of IL- 6 in the pathomechanism of inflammatory response in various forms of cerebral infarction could be more complex than previously assumed and confirm the need for further studies, both in the experimental models and clinical settings. The relationship between IL- 6 gene polymorphism and increased risk of cerebral infarction has been suggested [176, 177], although this was not confirmed by the other published results and further studies of this issue are required [178].

\section{Matrix Metalloproteinase-9}

MMP-9 is an inducible enzyme, representing a large family of over 20 proteinases, involved in degradation of the extracellular matrix and secreted by different components of NVU. In the course of acute ischemic stroke, MMP-9 function is related to disintegration of the components of extracellular matrix and disruption of BBB, through degradation of the basal lamina, in particular laminin, type IV collagen, and fibronectin [89, 179]. Compromising of BBB integrity results in extravasation of blood plasma and cells and in development of vasogenic edema and hemorrhagic transformation. This is especially the case when augmented by reperfusion in the ischemic tissue, resulting from dissolution of the embolus [180]. The results of experimental studies and clinical observations indicate the high level of MMP-9 to be associated not only with the infarct volume increase and progress of neurologic deficits but also with hemorrhagic transformation [89]. In the mouse model of transient ischemia, an increase of the MMP-9 expression was observed after $4 \mathrm{~h}$ of reperfusion and coexisted with the increase of infarct volume and neurological deficits [90]. Clinical study conducted on the group of 3186 patients with acute ischemic stroke revealed elevated MMP-9 serum levels, which were associated with higher risk of mortality and major disability [91]. Recently, it has been reported that MMP-9 can be used as a marker of the hemorrhagic transformation in the course of acute ischemic stroke [89]. On the basis of meta-analysis published by Wang and colleagues, the pooled sensitivity and specificity values of MMP-9 in predicting of hemorrhagic transformation in the course of acute ischemic stroke are $85 \%$ and $79 \%$, respectively [89]. Castellanos et al. [92] showed that plasma MMP-9 concentration on admission in patients with ischemic stroke who developed hemorrhagic transformation was significantly higher than in those who did not develop this complication, as well as in those from the control group. A predictive value of increased level of MMP-9, regarding threatening intracerebral hemorrhage, was raised in patients treated with thrombolytic therapy [93, 179]. Significantly increased plasma MMP-9 concentration $(191.4 \mathrm{ng} / \mathrm{ml})$ was detected in patients who later suffered from the parenchymal intracerebral 
hemorrhage in comparison to the control group $(68.05 \mathrm{ng} / \mathrm{ml})[93,94]$. Validation of the predictive capacity of MMP-9 pre-established cutoff value $(\geq$ $140 \mathrm{ng} / \mathrm{ml}$ ) for parenchymal hemorrhage development after thrombolytic therapy has been proved with sensitivity of $92 \%$ and specificity of $74 \%$ [95]. Characteristic MMP-9 concentration changes have been also revealed in the course of cardioembolic stroke [180]. The increased baseline values for MMP-9 levels can be treated as a predictor of hemorrhagic transformation which occurs between the 5th and 7th day, whereas peak of MMP-9 at $24 \mathrm{~h}$ time point can be a predictor for the early (occurring within $48 \mathrm{~h}$ ) parenchymal hematoma development. Apart from these, there is also some evidence suggesting positive role of MMP-9 in stroke recovery. Recent study by Abdelnaseer and colleagues [96] has shown increased MMP-9 levels during 30 days after stroke onset, which correlated with the improved patients' clinical status. However, explanation of the MMP-9 role in this phenomenon requires further studies. The MMP-9 could be also a useful biomarker for identification of threatening vasospasm following subarachnoid hemorrhage [181] and a predictor of delayed cerebral ischemia [182]. Some evidence indicates the MMP-9 gene polymorphism associated with the increased risk of ischemic stroke [183, 184]. Altogether, changes of the MMP-9 serum levels in the course of ischemic stroke are a signal of several pathophysiological processes, which determines its diagnostic value. Considering the wellknown negative effects of MMP-9 in the course of stroke, as well as some evidence indicating its positive function, it can be assumed that place of this marker in diagnosis of stroke is still not precisely defined and requires further basic and clinical studies.

\section{Tumor Necrosis Factor $a$}

$\mathrm{TNF} \alpha$ is expressed by macrophages and neurons in the infarcted area that enhances astrocytic and microglial inflammatory response in the course of ischemiareperfusion injury [97]. Its function is related to regulation of the cell death and inflammatory response $[98,185]$ and enhancement of glutamatergic excitotoxicity [99]. Through the NFKB-dependent signaling pathway, this cytokine can influence proliferative potential of the reactive astrocytes [186, 187]. An elevated level of the TNF $\alpha$ in blood serum has been revealed as a predictor of deteriorating neurological status of newborns after hypoxiaischemia injury [100]. Other study has shown that $\mathrm{TNF} \alpha$ could be a good indicator of the increased risk of ischemic brain damage after carotid artery stenting [101]. There is also well-documented evidence indicating that monitoring of TNF $\alpha$ and IL- $1 \beta$ levels can provide some valuable information allowing for diagnosis of stroke in patients with accompanying metabolic disorders and those without such complications. In patients with acute ischemic stroke and metabolic syndrome, higher TNF $\alpha$ and IL$1 \beta$ activation were observed, independently of stroke type (such as large artery atherosclerosis, lacunar and cardioembolic infarct), when compared to patients with the same types of stroke but without metabolic syndrome [102]. In the latter, the highest level of inflammatory response was observed in the cardioembolic stroke and the lowest in lacunar stroke. Additionally, an association has been found between the severity of neurological deficits on admission, intensity of inflammatory response, and stroke type [103]. In diabetic patients with lacunar stroke, activation levels of TNF $\alpha$ and IL-1 $\beta$ in the acute phase (24-72 h) and subacute phase (7-10 days) of stroke were lower, compared to non-diabetic patients, which could be associated with their better outcome [104]. Hence, TNF $\alpha$ and IL- $1 \beta$ plasma level assessment can be useful not only for diagnosis of different stroke types, but also their severity and accompanying metabolic disorders. Although some evidence suggests that TNF $\alpha$ gene polymorphism could be a predictor of the recurrent TIAs [188], the value of this factor for prediction of stroke risk is unequivocally assessed and requires further studies [189].

\section{von Willebrand factor}

vWF is a hemostatic agent secreted by the endothelial cells and megakaryocytes. It is involved in platelet adhesion, aggregation, and activation of complement system [190]. The $\mathrm{vWF}$ is a mediator of vascular inflammation which affects the release of IL-1 $\beta$, and TNF $\alpha$ [25]. The role of this factor as an ischemic biomarker has been extensively studied [191]. The elevated vWF serum levels have been reported as a predictor of an increased risk of the first ischemic stroke [105]. Other studies showed that vWF serum levels were higher in patients with the acute stroke and TIA than in those with chronic cerebrovascular disease [106, 192]. According to the Trial of Org 10172 in Acute Stroke Treatment (TOAST) classification, levels of vWF increase in all types of stroke in its acute phase, although after 3 months its increased concentration remains in the cardioembolic and cryptogenic stroke [107]. An association between elevated levels of vWF and the NIHSS score on admission and poor clinical outcome has been demonstrated, although not for the cardioembolic stroke [108]. The increase of the vWF levels has also been reported in the course of symptomatic carotid stenosis [106]. Reassuming, a coincidence between increased level of $\mathrm{vWF}$ and different types of ischemic stroke has been confirmed, making this factor a potential risk indicator of cerebrovascular diseases. What seems practically 
important is that the vWF levels differ among various clinical and etiological subtypes of ischemic stroke, which must be taken into account when conducting laboratory and clinical studies on this promising biomarker. High levels of vWF are associated with severity of stroke, as well as with poor clinical outcome.

\section{Interleukin-4}

This anti-inflammatory cytokine contributes to reduction of the acute ischemic damage and infarct volume, through the M2 microglia phenotype stimulation [109, 110]. IL-4 regulates infiltration of macrophages and phagocytic microglia into the ischemic area and an increase of expression of the other anti-inflammatory mediators [193]. Changes of the IL- 4 serum concentration, together with increase of the IL-6 serum levels, have been reported as diagnostically valuable in the acute phase of ischemic stroke [194]. An increase of expression of IL-4 receptor (IL-4R) is an independent predictor of worsening of the neurological status at $24 \mathrm{~h}$ after infarct onset [111]. Studies on the IL-4 gene polymorphism provide some valuable information concerning prognosis for patients with different types of ischemic stroke and related complications. The IL-4-gene $589 \mathrm{C}>\mathrm{T}$ polymorphism has a prognostic value for evaluation of developing stroke and prediction of the patient's functional impairment [195]. The C582T IL-4 gene polymorphism is an independent predictor of the thromboembolic stroke [196].

\section{Interleukin-10}

IL-10 is a cytokine of anti-inflammatory and neuroprotective function, released by astrocytes and microglia. It inhibits the production and secretion of IL-1 $\beta$ [197], TGF $\beta$ [198], and TNF $\alpha$ [199]. Other functions of this cytokine are related with suppression of neuronal apoptosis [200], neuroglial differentiation, and proliferation [201]. The IL10 expression increases in acute phase of ischemic stroke [112]. An association has been revealed between the IL10 serum levels and clinical status of patients with smallvessel disease and subcortical infarctions [113]. The increased IL-10 serum levels have been revealed in patients with severe neurological impairment assessed by NIHSS score at $48 \mathrm{~h}$ after the ischemic stroke onset [114]. However, some recent evidence suggests that IL-10 serum concentration negatively correlates with the increased risk of cerebral infarction [88]. Stroke patients with decreased serum levels of IL-10 $(<925.0 \mathrm{pg} / \mathrm{ml})$ demonstrate neurological deterioration within $72 \mathrm{~h}$ from the symptoms onset [112]. Therefore, the significance of IL-10 for assessment of ischemic stroke outcome and risk is ambiguous. These different aspects of IL-10 function in ischemic process are most likely related to its complex etiopathogenesis and depth of ischemic damage [169]. Recent studies have shown that the IL-10 gene polymorphism is associated with the incidence of ischemic stroke [202]. This association is even stronger among the cigarette smokers [203].

\section{Neurotrophic and Growth Factors}

The fourth group of potential stroke biomarkers is represented by the brain-derived neurotrophic factor (BDNF), glial cell line-derived neurotrophic factor (GDNF), and nerve growth factor (NGF). Neurotrophic factors could be considered an interesting supplement among the ischemic stroke diagnostic indicators, which results from their predictive value in assessment of neurological status and threatening complications. However, currently available results concerning dynamics of changes in expression of these markers in various types of stroke are fragmentary and frequently inconclusive.

\section{Brain-Derived Neurotrophic Factor}

BDNF is expressed by several constituents of NVU. Apart from neurons, it is also detected in astrocytes and microglial and ependymal cells, as well as in the endothelial cells of cerebral vessels, which reflects its important regulatory function $[204,205]$. In the ischemic stroke, it plays a neuroprotective role, associated mainly with modulation of signaling pathways, cytokine release, and suppression of apoptosis [115]. The results of experimental and clinical studies indicate a relationship between the BDNF serum levels and both functional recovery, as well as ischemic lesion volume [116, 206]. There is evidence indicating that lower BDNF serum level is associated with increased risk of stroke or TIA incidence [116]. Furthermore, a negative correlation was found between serum BDNF concentration on admission and infarct volume, assessed by DWI $(r=-0.363 ; P<0.001)$ in patients with acute ischemic stroke [206]. Recent studies show that this neurotrophin could be also used as a prognostic factor for prediction of the functional status of patients after ischemic stroke [117, 207]. The functional outcome based on the mRS examination performed on the 90th day after stroke onset was significantly worse in those patients whose BDNF level on the first day after admission was lower than $9.96 \pm 5.21 \mathrm{ng} / \mathrm{ml}$ [207]. Also, low BDNF levels were associated with poor functional outcome in long-term ( 2 and 7 years) follow-up studies [117]. The results of animal studies showed the improvement of neurological function after stroke, assessed with the modified Neurological Severity Score, with accompanying increase in BDNF concentration [118]. The BDNF can also be used as a diagnostic marker of the threatening post-stroke complications. Animal studies reveal an association between 
BDNF expression in hippocampus and intensity of the poststroke depression [119]. Clinical studies also indicate that BDNF could be an independent prognostic factor of the post-stroke depression. There is evidence indicating that patients suffering from post-stroke depression reveal significantly lower BDNF level than patients not suffering from this complication. Serum BDNF concentration < $5.86 \mathrm{ng} / \mathrm{ml}$ within $24 \mathrm{~h}$ after stroke onset is predictive for the danger of post-stroke depression development [208]. The results of experimental studies reveal also an association between the severity of cognitive impairment and BDNF concentration [120]. Some authors stress practically important differences in the BDNF levels detected in the whole blood and blood serum, which can result from its considerably high content in the blood cells. This must be taken into account while interpreting the diagnostic results relaying on assessment of the concentration of this neurotrophin [209].

\section{Glial Cell Line-Derived Neurotrophic Factor}

GDNF, being a representative of the transforming growth factor-beta family, is secreted by reactive astrocytes [210]. The results of animal studies suggest a potential value of this factor as a biomarker of neuroprotective and reparative processes. Its neuroprotective function relays among others on suppressing of free radical production. Through attenuation of the brain NO synthase activity, NO concentration is decreased, which prevents from glutamate-induced excitotoxic cell damage and consequently inhibits an expansion of infarcted area. By promoting cell survival, neurite outgrowth, and synaptogenesis, GDNF alleviates the ischemia-induced learning and memory disorders [121]. GDNF modulates astrogliosis and inflammatory response in the ischemic penumbra. One of its important physiological functions is protection against an early and delayed neuronal death [122, 123]. Antiapoptotic effect of GDNF is achieved through reduction of DNA fragmentation, and inhibition of the caspasedependent pathways. GDNF also induces the expression of anti-apoptotic genes (e.g., bcl-2 and bcl-xL). It enhances an antiautophagic effect within the lesioned brain area due to the antiapoptotic and antiautophagic functions. It modulates the post-stroke recovery and contributes to reduction of deleterious effect of ischemia. Characteristic for GDNF is its dynamic expression pattern [124, 211]. Depending on duration of the cerebral blood flow reduction, transient ischemia induces increase in GDNF mRNA expression lasting from $3 \mathrm{~h}$ to 3 days, with the peak of its expression at $6 \mathrm{~h}$. This early increase might be followed by a secondary peak at $72 \mathrm{~h}$. The highest GDNF immunoreactivity in astrocytes is observed between the $3 \mathrm{rd}$ and 7th day from the ischemia onset. Appearance of GDNF in the vascular system signalizes massive BBB damage, which is requisite for passage of this large molecule [125]. Overall, relatively early changes in GDNF expression could serve as valuable signal of reparative and neuroregenerative processes occurring within the ischemic area. However, further studies are necessary to verify significance of GDNF as an ischemic stroke biomarker.

\section{Nerve Growth Factor}

NGF is expressed by astrocytes and pericytes after stimulation by inflammatory mediators and proinflammatory cytokines [26, 212]. Neuroprotective function of NGF comprises inhibitory action upon apoptosis, resulting from reduced expression of caspase-3 and upregulation of Bcl-2 expression [126, 213]. It also antagonizes the activity of TNF $\alpha$ and IL- $1 \beta$ [127]. After transient cerebral ischemia in rats, NGF induces synaptogenesis which is related with improvement of cognitive and memory functions [128]. The available results of experimental studies indicate temporary increase of NGF expression detected in the cerebral cortex within $6 \mathrm{~h}$ after ischemia onset in mice [126]. In rats, there was temporary decline in the NGF content in brain since $4 \mathrm{~h}$ of reperfusion, with a gradual increase to normal levels between the 7th and 14th day. These changes are accompanied by an increase in NGF immunoreactivity in astrocytes [214]. After transient forebrain ischemia in gerbils, the NGF level decreased by $32 \%$ at 2 days after ischemia in the CA3 and dentate gyrus, whereas it increased by $50 \%$ after 2 weeks. These changes could be explained by cell death in the early phase and astrocytic reactivity in the later phase, respectively [215]. To our knowledge, up until now, there are no results published which refer to changes in NGF concentration in the blood serum of patients after ischemic stroke. However, the results of clinical studies showed decrease in NGF levels in the CSF of patients with ischemic cerebrovascular disease and cognitive impairment which confirms important role of this neurotrophin in neuroprotective processes [129]. Overall, determination of practical value of NGF as an ischemic biomarker requires further research. In particular, assessment of its concentration in the blood serum in various types of ischemic stroke would be required. Considering the involvement of NGF in neuroprotective processes, assessment of its changes could provide important diagnostic data.

\section{Perspectives for Identification of Effective Biomarkers of the Ischemic Stroke}

Although the results of experimental studies on numerous candidate stroke biomarkers and meta-analyses have been presented and discussed in many publications, so far, none of potential biomarkers have met clinical expectations $[3,4,8$, $216,217]$. Among the possible reasons mentioned by the experts in several publications, one can find methodological limitations of some studies, too small groups of analyzed 
patients, inadequate validation of results, difficulties in determination of stroke etiology, imprecise stratification of patients according to identified risk factors and clinical conditions, identification of other coexisting diseases, differently defined endpoints, and, finally, inadequately chosen control groups. On the other hand, failures in finding suitable ischemic stroke biomarkers can result from the heterogeneity of the cerebral stroke itself [8]. This is the consequence of pathophysiological processes occurring with different intensity in various etiopathological types of stroke, additionally complicated by different course of these processes in individual patients being the result of differences in their metabolism, age, ethnic differences, or presence of coexisting diseases. It has been postulated that the greatest chance for clinical application can have diagnostic panels composed of biomarkers characteristic for specific types of stroke $[216,218]$. Biomarkers in these panels should be representative for pathophysiological processes, such as oxidative stress, necrotic and apoptotic cell death, BBB disintegration and brain edema, inflammatory response, and thrombosis. According to this approach, specificity of particular types of stroke, such as large- or small-vessel disease, lacunar stroke, and cardioembolic stroke, should be also taken into account.

An ischemic stroke is a heterogeneous process which cannot be adequately signalized by activation of a single biomarker. Therefore, it is critically important to evaluate a broad range of molecules involved in pathophysiology of stroke, to identify and choose a set of potentially the best indicators of this process [6]. Recent studies of the blood-derived 21 biomarkers containing diagnostic panel, conducted in order to differentiate between real strokes and stroke mimics and between ischemic and hemorrhagic strokes in the hyperacute phase, have failed to provide a conclusive solution, due to insufficient accuracy of differential diagnosis [219]. Therefore, searching for more effective markers of ischemic stroke still remains in the focus of interest of experts, representing different disciplines [3, 220]. Future studies will undoubtedly concentrate on isolation of substances, representing different chemical structures and creating diagnostic panels, representative for several pathophysiological processes of ischemic stroke [8, 217]. Hence, it seems justified to plan a new search for biomarkers based on several premises, resulting from the current state of knowledge of the ischemic stroke pathophysiology. Among these, the following factors should be taken into account: (1) morphological and functional specificity of cellular components of damaged tissue; (2) different resistance of various NVU components to decreased cerebral blood flow and glucose availability, enabling adaptation of metabolic processes to anaerobic conditions; (3) disintegration of neurotransmitter and signaling pathways; (4) limited sensitivity and specificity of biomarkers, resulting from their expression by several constituents of NVU and in the course of different pathological processes, such as cerebral hemorrhage, inflammation, or neurodegenerative diseases; (5) complex character of inflammatory response to ischemia; (6) simultaneous activation of several pathological processes (e.g., oxidative stress, thrombosis, brain edema, and hemorrhagic transformation), related to secretion of numerous markers; (7) dynamic character of biomarker expression, resulting in reaching their peaks at different time points after ischemia onset; (8) occurrence of various combinations of biomarkers, activated in different types of ischemic stroke (e.g., cardioembolic, lacunar, large-vessel disease); (9) patients' age and coexistence of other diseases (e.g., cardiovascular, neurodegenerative, metabolic, inflammatory) influencing the ischemic biomarkers expression; (10) need for elaboration of complex diagnostic protocols, based on the standardized assessment of biomarker panels which should be used in combination with neuroradiological imaging studies and evaluation of gene expression and polymorphism.

In this review, we have concentrated on a selection of substances, which are representative for the components of NVU and released from the brain into blood or CSF after stroke. According to this approach, the new diagnostic panels should contain the representatives of glial proteins (e.g., S100 $\beta$, GFAP, AQP4), pro- and anti-inflammatory cytokines (IL-4, IL-6, IL-10, TNF $\alpha$, MMP-9), factors representing hemostatic system (vWF), markers of NVU metabolism (FABPs, NSE) and neurotransmitter synthesis (GS, SR), representatives of amino acid neurotransmitters (e.g., Glu, GABA, Gly, Ser), and, finally, neurotrophic and growth factors (BDNF, GDNF, NGF). Representation of different biochemical and functional categories by the abovementioned substances will enable monitoring of main pathophysiological processes, which occur during NVU damage. However, in several cases of the presented potential candidates for stroke biomarkers, available data related with their function are based only on experimental studies and not supported with sufficient clinical evaluation, in particular, concerning their role in various types of stroke. This justifies the need for further studies aimed at verification of their diagnostic utility.

Apart from the abovementioned functional division, another one based on the time point of expression in relation to the onset of stroke symptoms may be of practical value [8]. Assessment of ischemic stroke indicators (e.g., proinflammatory cytokines and hemostatic factors) in patients with known risk factors, prior to the onset of stroke symptoms, may have diagnostic and screening value and allow for selection of "at risk" of stroke individuals. It may also have some therapeutic value, justifying the inclusion of these patients into the group for primary prevention. Monitoring of biomarkers in the acute phase of stroke could be of great diagnostic importance. It relies on differentiation between stroke patients and the negative control individuals (biomarkers: S100 $\beta$, IL-6, MMP-9, $\mathrm{TNF} \alpha$, and $\mathrm{vWF}$ ), exclusion of stroke mimics, such as migraine, epilepsy, structural brain lesions (S100 $\beta$, MMP-9), 
and differentiation between ischemic and hemorrhagic stroke (GFAP, S100ß) [3, 216, 217]. Many of the NVU-derived markers could be used for assessment of the risk of strokerelated complications. These include hemorrhagic transformation of the ischemic stroke (S-100 $\beta$, vWF, and MMP-9), development of malignant stroke $(\mathrm{S} 100 \beta)$, increasing infarct volume (S-100 $\beta$, NSE, MMP-9, IL-6, TNF $\alpha$, and Glu), early neurological deterioration and progressive (unstable) stroke or death (IL-6, S100 $\beta$, TNF $\alpha$, MMP-9; NSE, Glu, and GABA) $[3,217,221]$. Furthermore, there are premises suggesting value of some biomarkers in the diagnosis of specific stroke types, such as cardioembolic stroke (vWF, TNF $\alpha$ ), hemorrhagic stroke (GFAP, MMP-9), large- and small-artery disease (IL-6; TNF $\alpha$ ), or lacunar stroke (Glu, GABA) [3, 66, 217, $221]$. Potential benefits resulting from the ischemic biomarkers' assessment in the later phase of stroke can be related with information about its progression (biomarkers: GFAP, S100 $\beta$, IL-6, MMP-9), monitoring of the results of therapy (IL-6, S100ß, MMP-9), and estimation of the outcome prognosis (IL-6, S100ß, vWF; BDNF) [3, 217, 221].

\section{Neurovascular Unit-Based Approach to Selection of New Ischemic Stroke Biomarkers}

Proposed in this review approach, based on the NVU concept, for selection of potential ischemic stroke biomarkers takes into account the complexity of brain tissue and functional relationships between its cellular components. For example, the ischemic lesion affecting perivascular axonal terminals, together with the astrocytic end-foots and functional BBB, can be manifested by a changed concentration of specific biomarkers (e.g., AQP4, BDNF, GFAP, NGF, and vWF) signaling the extent and dynamics of brain damage. Similarly, disintegration of structural and functional relationships between neurons and astrocytes results in decreased level of energetic metabolism, dysfunction of tripartite synapse and impaired gliotransmission, which is signalized by release of several biomarkers (e.g., FABPs, GFAP, S100 $\beta$, GABA, Glu, and NSE). Furthermore, the NVU involvement in inflammatory response initiated by ischemic process can be inferred from increased secretion of characteristic mediators (e.g., IL-4, IL-6, IL-10, MMP-9, vWF) and their transfer into the vascular system. Thus, the NVU concept proves to be useful not only for selection of potential biomarkers, representing different components of this unit, but also for determination of those of them, which are representative for pathophysiological processes occurring at different phases of stroke. In our view, another possibility for application of the NVU concept for improvement of cerebral stroke diagnosis could be related with development of methods, which combine the results of morphological studies on distribution and concentration of selected markers (e.g., AQP4, amino acids, and metabolites) with the results of neuroradiological studies, assessing the depth of cerebral blood flow disturbances, evolution of brain edema and penumbra.

\section{Summary and Conclusion}

Ischemic stroke is a dynamic process which consequences result from the coexistence of several phenomena, such as oxidative stress, immunological response, reactive gliosis, and dysfunction of hemostatic system. In spite of continuous development of new diagnostic methods, recognition of the cerebral ischemic infarct, especially in its acute phase, is often very difficult or even impossible. Despite activation of numerous markers, their diagnostic value is not satisfactory and requires further investigation, especially in different types of stroke. This justifies the approach relying on selection of several potential markers, characterized by acceptable sensitivity and specificity, associated with acute or later phases of stroke and representative for various pathophysiological processes. Taking into account still unsatisfactory results of studies on ischemic stroke biomarkers, it may be assumed that further efforts in this area will concentrate on searching for new components of diagnostic panels representing various elements of NVU. New complex diagnostic protocols will include analysis of biomarkers' content, neuroradiological studies, and patient's genetic profile, including the gene polymorphism studies associated with an increased risk of stroke and its complications.

Acknowledgments Aleksandra Steliga wrote the article, and contributed to the manuscript concept and final edition.

Przemysław Kowiański was responsible for the manuscript concept and design, contributed to manuscript writing and preparation of revised version of manuscript, and coordinated editorial plan.

Ewelina Czuba was responsible for the literature search, figures' concept, and manuscript edition.

Monika Waśkow was responsible for the literature search and selection.

Janusz Moryś contributed to the manuscript concept and final critical review.

Grażyna Lietzau contributed to the manuscript concept and preparation of revised version of manuscript, critical revision and final edition.

All authors critically reviewed content and approved the final version of this publication.

\section{Compliance with Ethical Standards}

The authors declare that they have no conflict of interest.

Ethical Approval This article does not contain any studies with human participants or animals performed by any of the authors. 
Open Access This article is distributed under the terms of the Creative Commons Attribution 4.0 International License (http:// creativecommons.org/licenses/by/4.0/), which permits unrestricted use, distribution, and reproduction in any medium, provided you give appropriate credit to the original author(s) and the source, provide a link to the Creative Commons license, and indicate if changes were made.

\section{References}

1. Chalela JA, Kidwell CS, Nentwich LM, Luby M, Butman JA, Demchuk AM, et al. Magnetic resonance imaging and computed tomography in emergency assessment of patients with suspected acute stroke: a prospective comparison. Lancet. NIH Public Access; 2007 [cited 2019 Aug 27];369:293-298. Available from: http://www.ncbi.nlm.nih.gov/pubmed/17258669.

2. Amarenco P, Bogousslavsky J, Caplan LR, Donnan GA, Hennerici MG. Classification of stroke subtypes. Cerebrovasc. Dis. 2009 Karger Publishers [cited 2019 Aug 27]. p. 493-501. Available from: http://www.ncbi.nlm.nih.gov/pubmed/19342825.

3. Katan M, Elkind MS. The potential role of blood biomarkers in patients with ischemic stroke. Clin Transl Neurosci. 2018 SAGE PublicationsSage UK: London, England; [cited 2018 Dec 12];2: 2514183X1876805. Available from: http://journals.sagepub.com/ doi/10.1177/2514183X18768050

4. Whiteley W, Tseng MC, Sandercock P. Blood biomarkers in the diagnosis of ischemic stroke: a systematic review. Stroke. 2008 [cited 2018 Dec 8]. p. 2902-9. Available from: http:// www.ncbi.nlm.nih.gov/pubmed/18658039.

5. Atkinson AJ, Colburn WA, DeGruttola VG, DeMets DL, Downing GJ, Hoth DF, et al. Biomarkers and surrogate endpoints: preferred definitions and conceptual framework. Clin. Pharmacol. Ther. 2001 [cited 2019 Aug 27]. p. 89-95. Available from: http:// www.ncbi.nlm.nih.gov/pubmed/11240971.

6. Hasan N, McColgan P, Bentley P, Edwards RJ, Sharma P. Towards the identification of blood biomarkers for acute stroke in humans: a comprehensive systematic review. Br J Clin Pharmacol. 2012 [cited 2018 Dec 8];74:230-40. Available from: http:// www.ncbi.nlm.nih.gov/pubmed/22320313.

7. Jickling GC, Sharp FR. Biomarker panels in ischemic stroke. Stroke. 2015 [cited 2018 Dec 8];46:915-20. Available from: http://www.ncbi.nlm.nih.gov/pubmed/25657186.

8. Makris K, Haliassos A, Chondrogianni M, Tsivgoulis G. Blood biomarkers in ischemic stroke: potential role and challenges in clinical practice and research. Crit. Rev. Clin. Lab. Sci. 2018 [cited 2018 Dec 12]. p. 294-328. Available from: http:// www.ncbi.nlm.nih.gov/pubmed/29668333.

9. Del Zoppo GJ. Toward the neurovascular unit A journey in clinical translation: 2012 Thomas Willis lecture. Stroke. 2013 [cited 2018 Dec 8];44:263-269. Available from: http:// www.ncbi.nlm.nih.gov/pubmed/23033344.

10. Kowiański P, Lietzau G, Steliga A, Waśkow M, Moryś J. The astrocytic contribution to neurovascular coupling - still more questions than answers? . Neurosci. Res. 2013. p. 171-83. Available from: http://www.sciencedirect.com/science/article/pii/ S0168010213000369?via\%3Dihub

11. Iadecola C. The Neurovascular unit coming of age: a journey through neurovascular coupling in health and disease. Neuron. 2017 [cited 2018 Dec 8]. p. 17-42. Available from: http:// www.ncbi.nlm.nih.gov/pubmed/28957666.

12. Dambinova SA, Khounteev GA, Skoromets AA. Multiple panel of biomarkers for TIA/stroke evaluation. Stroke. 2002 [cited 2018
Dec 8]. p. 1181-2. Available from: https:/www.ahajournals.org/ doi/10.1161/01.STR.0000014922.83673.86

13. Reynolds MA, Kirchick HJ, Dahlen JR, Anderberg JM, McPherson PH, Nakamura KK, et al. Early biomarkers of stroke. Clin Chem. 2003 [cited 2018 Dec 8]. p. 1733-9. Available from: http://www.ncbi.nlm.nih.gov/pubmed/14500614.

14. Magaki SD, Williams CK, Vinters H V. Glial function (and dysfunction) in the normal \& ischemic brain . Neuropharmacology. 2018 [cited 2018 Dec 8]. p. 218-25. Available from: http:// www.ncbi.nlm.nih.gov/pubmed/29122627.

15. Del Zoppo GJ. The neurovascular unit in the setting of stroke. J Intern Med. 2010 [cited 2018 Dec 8]. p. 156-71. Available from: http://www.ncbi.nlm.nih.gov/pubmed/20175864.

16. Girouard H. Neurovascular coupling in the normal brain and in hypertension, stroke, and Alzheimer disease. J Appl Physiol. 2006 [cited 2018 Dec 8];100:328-335. Available from: http:// www.ncbi.nlm.nih.gov/pubmed/16357086.

17. Cavaglia M, Dombrowski SM, Drazba J, Vasanji A, Bokesch PM, Janigro D. Regional variation in brain capillary density and vascular response to ischemia. Brain Res. 2001 [cited 2018 Dec 8];910:81-93. Available from: http://www.ncbi.nlm.nih.gov/ pubmed/11489257.

18. Dohmen C, Kumura E, Rosner G, Heiss WD, Graf R. Extracellular correlates of glutamate toxicity in short-term cerebral ischemia and reperfusion: a direct in vivo comparison between white and gray matter. Brain Res. 2005 [cited 2018 Dec 8];1037:43-51. Available from: http:// www.ncbi.nlm.nih.gov/pubmed/15777751.

19. Guo ZH, Li F, Wang WZ. The mechanisms of brain ischemic insult and potential protective interventions . Neurosci. Bull. 2009 [cited 2018 Dec 8]. p. 139-52. Available from: http:// www.ncbi.nlm.nih.gov/pubmed/19448688.

20. Manzanero S, Santro T, Arumugam T V. Neuronal oxidative stress in acute ischemic stroke: sources and contribution to cell injury. Neurochem. Int. 2013 [cited 2018 Dec 8]. p. 712-8. Available from: http://www.ncbi.nlm.nih.gov/pubmed/23201332.

21. Wang LY, Liu J, Li Y, Li B, Zhang YY, Jing ZW, et al. Timedependent variation of pathways and networks in a 24-hour window after cerebral ischemia-reperfusion injury. BMC Syst Biol. BioMed Central; 2015 [cited 2018 Dec 8];9:11. Available from: http://www.biomedcentral.com/1752-0509/9/11

22. Tang X, Zhong W, Tu Q, Ding B. NADPH oxidase mediates the expression of MMP-9 in cerebral tissue after ischemiareperfusion damage. Neurol Res. Taylor \& Francis; 2014 [cited 2018 Dec 8];36:118-125. Available from: http://www. tandfonline.com/doi/full/10.1179/1743132813Y.0000000266

23. Liebner S, Dijkhuizen RM, Reiss Y, Plate KH, Agalliu D, Constantin G. Functional morphology of the blood-brain barrier in health and disease. Acta Neuropathol. 2018 [cited 2018 Dec 8]. p. 311-36. Available from: http://www.ncbi.nlm.nih.gov/pubmed/ 29411111.

24. Stanimirovic D, Satoh K. Inflammatory mediators of cerebral endothelium: a role in ischemic brain inflammation. Brain Pathol . 2000 [cited 2018 Dec 8];10:113-126. Available from: http:// www.ncbi.nlm.nih.gov/pubmed/10668901.

25. Gragnano F, Sperlongano S, Golia E, Natale F, Bianchi R, Crisci $\mathrm{M}$, et al. The role of von Willebrand factor in vascular inflammation: from pathogenesis to targeted therapy. Mediators Inflamm. 2017 [cited 2018 Dec 8]. p. 1-13. Available from: http:// www.ncbi.nlm.nih.gov/pubmed/28634421.

26. Ishitsuka K, Ago T, Arimura K, Nakamura K, Tokami H, Makihara N, et al. Neurotrophin production in brain pericytes during hypoxia: a role of pericytes for neuroprotection. Microvasc Res. 2012 [cited 2018 Dec 8];83:352-359. Available from: http://www.ncbi.nlm.nih.gov/pubmed/22387236. 
27. Badaut J, Lasbennes F, Magistretti PJ, Regli L. Aquaporins in brain: distribution, physiology, and pathophysiology. J. Cereb. Blood Flow Metab. 2002 [cited 2018 Dec 8]. p. 367-78. Available from: http://www.ncbi.nlm.nih.gov/pubmed/11919508.

28. Badaut J, Ashwal S, Tone B, Regli L, Tian HR, Obenaus A. Temporal and regional evolution of aquaporin-4 expression and magnetic resonance imaging in a rat pup model of neonatal stroke. Pediatr Res. 2007 [cited 2018 Dec 8];62:248-254. Available from: http://www.ncbi.nlm.nih.gov/pubmed/17622964.

29. Sofroniew M V., Vinters H V. Astrocytes: biology and pathology. Acta Neuropathol. 2010 [cited 2018 Dec 8]. p. 7-35. Available from: http://www.ncbi.nlm.nih.gov/pubmed/20012068.

30. Liddelow SA, Barres BA. Reactive astrocytes: production, function, and therapeutic potential. Immunity. 2017 [cited 2018 Dec 9]. p. 957-67. Available from: http://www.ncbi.nlm.nih.gov/ pubmed/28636962.

31. Magistretti PJ, Allaman I. A cellular perspective on brain energy metabolism and functional imaging. Neuron. 2015 [cited 2018 Dec 9]. p. 883-901. Available from: http:// www.ncbi.nlm.nih.gov/pubmed/25996133.

32. Barr TL, Conley Y, Ding J, Dillman A, Warach S, Singleton A, et al. Genomic biomarkers and cellular pathways of ischemic stroke by RNA gene expression profiling. Neurology. 2010 [cited 2018 Dec 9];75:1009-1014. Available from: http:// www.ncbi.nlm.nih.gov/pubmed/20837969.

33. Stamova B, Xu H, Jickling G, Bushnell C, Tian Y, Ander BP, et al. Gene expression profiling of blood for the prediction of ischemic stroke. Stroke. 2010 [cited 2018 Dec 9];41:2171-2177. Available from: http://www.ncbi.nlm.nih.gov/pubmed/20798371.

34. Xiong ZG, Zhu XM, Chu XP, Minami M, Hey J, Wei WL, et al. Neuroprotection in ischemia: blocking calcium-permeable acidsensing ion channels. Cell. Cell Press; 2004 [cited 2019 Aug 27];118:687-698. Available from: https://www. sciencedirect.com/science/article/pii/S0092867404008050?via\% 3Dihub

35. Sofroniew M V. Molecular dissection of reactive astrogliosis and glial scar formation. Trends Neurosci. 2009 [cited 2018 Dec 9]. p. 638-47. Available from: http://www.ncbi.nlm.nih.gov/pubmed/ 19782411.

36. Dvorak F, Haberer I, Sitzer M, Foerch C. Characterisation of the diagnostic window of serum glial fibrillary acidic protein for the differentiation of intracerebral haemorrhage and ischaemic stroke. Cerebrovasc Dis. 2009 [cited 2018 Dec 9];27:37-41. Available from: http:/www.ncbi.nlm.nih.gov/pubmed/19018136.

37. Foerch C, Curdt I, Yan B, Dvorak F, Hermans M, Berkefeld J, et al. Serum glial fibrillary acidic protein as a biomarker for intracerebral haemorrhage in patients with acute stroke. J Neurol Neurosurg Psychiatry. BMJ Publishing Group; 2006 [cited 2018 Dec 9];77:181-184. Available from: http:// www.ncbi.nlm.nih.gov/pubmed/16174653.

38. Brouns R, De Vil B, Cras P, De Surgeloose D, Mariën P, De Deyn PP. Neurobiochemical markers of brain damage in cerebrospinal fluid of acute ischemic stroke patients. Clin Chem. 2010 [cited 2018 Dec 9];56:451-458. Available from: http:// www.ncbi.nlm.nih.gov/pubmed/19959621.

39. Honda M, Tsuruta R, Kaneko T, Kasaoka S, Yagi T, Todani M, et al. Serum glial fibrillary acidic protein is a highly specific biomarker for traumatic brain injury in humans compared with S100B and neuron-specific enolase. J Trauma - Inj Infect Crit Care. 2010 [cited 2019 Aug 27];69:104-109. Available from: http://www.ncbi.nlm.nih.gov/pubmed/20093985.

40. Barger SW, Van Eldik LJ, Mattson MP. S100 $\beta$ protects hippocampal neurons from damage induced by glucose deprivation. Brain Res. 1995 [cited 2018 Dec 9];677:167-170. Available from: http://www.ncbi.nlm.nih.gov/pubmed/7606463.
41. Van Eldik LJ, Wainwright MS. The Janus face of glial-derived S100B: beneficial and detrimental functions in the brain. Restor Neurol Neurosci. 2003 [cited 2018 Dec 9];21:97-108. Available from: http://www.ncbi.nlm.nih.gov/pubmed/14530573.

42. Adami C, Bianchi R, Pula G, Donato R. S100B-stimulated NO production by $\mathrm{BV}-2$ microglia is independent of RAGE transducing activity but dependent on RAGE extracellular domain. Biochim Biophys Acta - Mol Cell Res. 2004 [cited 2018 Dec 9]. p. 169-77. Available from: http://www.ncbi.nlm.nih.gov/pubmed/ 15590067.

43. Foerch C, Otto B, Singer OC, Neumann-Haefelin T, Yan B, Berkefeld J, et al. Serum S100B predicts a malignant course of infarction in patients with acute middle cerebral artery occlusion. Stroke. 2004 [cited 2018 Dec 9];35:2160-2164. Available from: http://www.ncbi.nlm.nih.gov/pubmed/15297628.

44. Aurell A, Rosengren LE, Karlsson B, Olsson JE, Zbornikova V, Haglid KG. Determination of S-100 and glial fibrillary acidic protein concentrations in cerebrospinal fluid after brain infarction. Stroke. 1991 [cited 2019 Aug 27];22:1254-1258. Available from: http://www.ncbi.nlm.nih.gov/pubmed/1926235.

45. Petzold A, Michel P, Stock M, Schluep M. Glial and axonal body fluid biomarkers are related to infarct volume, severity, and outcome. J Stroke Cerebrovasc Dis. 2008 [cited 2019 Aug 27]; 17: 196-203. Available from: http://www.ncbi.nlm.nih.gov/pubmed/ 18589339.

46. Hsu Y, Tran M, Linninger AA. Dynamic regulation of aquaporin4 water channels in neurological disorders. Croat Med J. Medicinska Naklada; 2015 [cited 2018 Dec 9];56:401-21. Available from: http://www.ncbi.nlm.nih.gov/pubmed/26526878.

47. Manley GT, Zador Z, Stiver S, Wang V. Role of aquaporin-4 in cerebral edema and stroke. Handb. Exp. Pharmacol. 2009 Berlin, Heidelberg: Springer Berlin Heidelberg; [cited 2018 Dec 9]. p. 159-70. Available from: http://www.ncbi.nlm.nih.gov/pubmed/ 19096776.

48. $\mathrm{He} \mathrm{ZP}, \mathrm{Lu} \mathrm{H}$. Aquaporin-4 gene silencing protects injured neurons after early cerebral infarction. Neural Regen Res. 2015 [cited 2018 Dec 9];10:1082-1087. Available from: http:// www.ncbi.nlm.nih.gov/pubmed/26330830.

49. Suzuki Y, Nakamura Y, Yamada K, Huber VJ, Tsujita M, Nakada T. Aquaporin-4 positron emission tomography imaging of the human brain: first report. J Neuroimaging . 2013 [cited 2018 Dec 9];23:219-223. Available from: http:// www.ncbi.nlm.nih.gov/pubmed/22817997.

50. Wunderlich MT, Hanhoff T, Goertler M, Spener F, Glatz JFC, Wallesch $\mathrm{CW}$, et al. Release of brain-type and heart-type fatty acid-binding proteins in serum after acute ischaemic stroke. $\mathrm{J}$ Neurol. 2005 [cited 2018 Dec 9];252:718-724. Available from: http://www.ncbi.nlm.nih.gov/pubmed/15834650.

51. Glatz JFC, Van Der Vusse GJ. Cellular fatty acid-binding proteins: their function and physiological significance. Prog Lipid Res. 2018 Pergamon; 1996 [cited 9];35:243-82. Available from: https://www.sciencedirect.com/science/article/pii/ S0163782796000069

52. Myers-Payne SC, Hubbell T, Pu L, Schnütgen F, Börchers T, Wood WG, et al. Isolation and characterization of two fatty acid binding proteins from mouse brain. J Neurochem. 2018 John Wiley \& Sons, Ltd; 1996 [cited 9];66:1648-56. Available from: http://doi.wiley.com/10.1046/j.1471-4159.1996.66041648.x

53. Zimmermann-Ivol CG, Burkhard PR, Le Floch-Rohr J, Allard L, Hochstrasser DF, Sanchez J-C. Fatty acid binding protein as a serum marker for the early diagnosis of stroke. Mol Cell Proteomics. 2004 [cited 2018 Dec 9];3:66-72. Available from: http://www.ncbi.nlm.nih.gov/pubmed/14581522.

54. Castillo J, Dávalos A, Noya M. Progression of ischaemic stroke and excitotoxic aminoacids. Lancet. 1997 [cited 2018 Dec 9];349: 
79-83. Available from: http://www.ncbi.nlm.nih.gov/pubmed/ 8996418.

55. Castillo J, Dávalos A, Naveiro J, Noya M. Neuroexcitatory amino acids and their relation to infarct size and neurological deficit in ischemic stroke. Stroke. 1996 [cited 2018 Dec 9];27:1060-1065. Available from: http://www.ncbi.nlm.nih.gov/pubmed/8650715.

56. Dávalos A, Castillo J, Serena J, Noya M. Duration of glutamate release after acute ischemic stroke. Stroke. 1997 [cited 2018 Dec 9];28:708-710. Available from: http:// www.ncbi.nlm.nih.gov/pubmed/9099183.

57. Pérez-Torres I, Zuniga-Munoz AM, Guarner-Lans V. Beneficial effects of the amino acid glycine. Mini Rev Med Chem. 2017 [cited 2019 mar 5];17:15-32. Available from: http:// www.ncbi.nlm.nih.gov/pubmed/27292783.

58. Zeilhofer HU, Acuña MA, Gingras J, Yévenes GE. Glycine receptors and glycine transporters: targets for novel analgesics? Cell. Mol. Life Sci. 2018 [cited 2019 Mar 5]. p. 447-65. Available from: http://www.ncbi.nlm.nih.gov/pubmed/28791431.

59. Boison D. The biochemistry and epigenetics of epilepsy: focus on adenosine and glycine. Front Mol Neurosci. 2016 [cited 2019 mar 5];9:26. Available from: http://www.ncbi.nlm.nih.gov/pubmed/ 27147960.

60. Goulart VAM, Sena MM, Mendes TO, Menezes HC, Cardeal ZL, Paiva MJN, et al. Amino acid biosignature in plasma among ischemic stroke subtypes. Biomed Res Int. 2019 Hindawi; [cited 2019 Aug 28];2019:1-11. Available from: https://www.hindawi. com/journals/bmri/2019/8480468/

61. Park J. Movement Disorders following cerebrovascular lesion in the basal ganglia circuit. J Mov Disord. 2016 Korean Movement Disorders Society; [cited 2019 mar 5];9:71-9. Available from: http://www.ncbi.nlm.nih.gov/pubmed/27240808.

62. Kang JQ. Defects at the crossroads of GABAergic signaling in generalized genetic epilepsies. Epilepsy Res. 2017 [cited 2019 Mar 5]. p. 9-18. Available from: https://linkinghub.elsevier.com/ retrieve/pii/S0920121117302504

63. Babaev O, Piletti Chatain C, Krueger-Burg D. Inhibition in the amygdala anxiety circuitry. Exp. Mol. Med. 2018 [cited 2019 Mar 5]. p. 18. Available from: http://www.ncbi.nlm.nih.gov/pubmed/ 29628509.

64. Wideman CE, Jardine KH, Winters BD. Involvement of classical neurotransmitter systems in memory reconsolidation: focus on destabilization. Neurobiol. Learn. Mem. 2018 Academic Press; [cited 2019 Mar 5]. p. 68-79. Available from: https://www. sciencedirect.com/science/article/pii/S1074742718302569

65. Bast T, Pezze M, McGarrity S. Cognitive deficits caused by prefrontal cortical and hippocampal neural disinhibition. Br. J. Pharmacol. 2017 [cited 2019 Mar 5]. p. 3211-25. Available from: http://doi.wiley.com/10.1111/bph.13850

66. Serena J, Leira R, Castillo J, Pumar JM, Castellanos M, Dávalos A. Neurological deterioration in acute lacunar infarctions: the role of excitatory and inhibitory neurotransmitters. Stroke. 2001 [cited 2018 Dec 9];32:1154-1161. Available from: http:// www.ncbi.nlm.nih.gov/pubmed/11340225.

67. Erecińska M, Nelson D, Wilson DF, Silver IA. Neurotransmitter amino acids in the CNS. I. Regional changes in amino acid levels in rat brain during ischemia and reperfusion. Brain Res. 1984 [cited 2019 Aug 28];304:9-22. Available from: http:// www.ncbi.nlm.nih.gov/pubmed/6146383.

68. Sims NR. The stimulus-evoked release of glutamate and GABA from brain subregions following transient forebrain ischemia in the rat. Neurochem Res. 1993 [cited 2019 Aug 28];18:10731079. Available from: http://www.ncbi.nlm.nih.gov/pubmed/ 7902957.

69. Qian Z, Lin Y, Xing J, Qiu Y, Ren L. Expression and functions of Glutamate and $\gamma$-aminobutyric acid transporters in ischemic models. Mol Med Rep. 2018 [cited 2019 Aug 28];17:8196-
8202. Available from: http://www.ncbi.nlm.nih.gov/pubmed/ 29693164

70. Abe T, Suzuki M, Sasabe J, Takahashi S, Unekawa M, Mashima $\mathrm{K}$, et al. Cellular origin and regulation of $\mathrm{D}$ - and $\mathrm{L}$-serine in in vitro and in vivo models of cerebral ischemia. J Cereb Blood Flow Metab. 2014 SAGE Publications; [cited 2018 Dec 9];34: 1928-35. Available from: http://www.ncbi.nlm.nih.gov/pubmed/ 25294127.

71. Mustafa AK, Ahmad AS, Zeynalov E, Gazi SK, Sikka G, Ehmsen JT, et al. Serine racemase deletion protects against cerebral ischemia and excitotoxicity. J Neurosci. 2010 NIH Public Access; [cited 2018 Dec 9];30:1413-6. Available from: http:// www.ncbi.nlm.nih.gov/pubmed/20107067.

72. Lee A, Lingwood BE, Bjorkman ST, Miller SM, Poronnik P, Barnett NL, et al. Rapid loss of glutamine synthetase from astrocytes in response to hypoxia: Implications for excitotoxicity. J Chem Neuroanat. 2010 [cited 2018 Dec 9];39:211-20. Available from: http://www.ncbi.nlm.nih.gov/pubmed/20034557.

73. Jeitner TM, Battaile K, Cooper AJL. Critical Evaluation of the changes in glutamine synthetase activity in models of cerebral stroke. Neurochem Res. 2015 [cited 2018 Dec 9];40:2544-2556. Available from: http://www.ncbi.nlm.nih.gov/pubmed/26233464.

74. Gao J, Yang H, Chen J, Fang J, Chen C, Liang R, et al. Analysis of serum metabolites for the discovery of amino acid biomarkers and the effect of galangin on cerebral ischemia. Mol Biosyst. 2013 [cited 2018 Dec 9];9:2311-2321. Available from: http:// www.ncbi.nlm.nih.gov/pubmed/23793526.

75. Lee DR, Helps SC, Gibbins IL, Nilsson M, Sims NR. Losses of NG2 and NeuN immunoreactivity but not astrocytic markers during early reperfusion following severe focal cerebral ischemia. Brain Res. 2003 [cited 2018 Dec 9];989:221-230. Available from: http://www.ncbi.nlm.nih.gov/pubmed/14556944.

76. Wang L, Zhu X. Serine racemase expression in mouse cerebral cortex after permanent focal cerebral ischemia. Acta Pharmacol Sin. 2004 [cited 2018 Dec 9];25:436-441. Available from: http:// www.ncbi.nlm.nih.gov/pubmed/15066209.

77. Zuo L, Zhan Y, Liu F, Chen C, Xu L, Calic Z, et al. Clinical and laboratory factors related to acute isolated vertigo or dizziness and cerebral infarction. Brain Behav. 2018 Wiley-Blackwell; [cited 2018 Dec 9];8:e01092. Available from: http:// www.ncbi.nlm.nih.gov/pubmed/30099862.

78. Kim BJ, Kim YJ, Ahn SH, Kim NY, Kang DW, Kim JS, et al. The second elevation of neuron-specific enolase peak after ischemic stroke is associated with hemorrhagic transformation. J Stroke Cerebrovasc Dis. 2014 [cited 2018 Dec 9];23:2437-2443. Available from: http://www.ncbi.nlm.nih.gov/pubmed/25183561.

79. Stammet P. Blood biomarkers of hypoxic-ischemic brain injury after cardiac arrest. Semin Neurol. 2017 [cited 2018 Dec 9];37: 75-80. Available from: http://www.ncbi.nlm.nih.gov/pubmed/ 28147421 .

80. Iłżecki M, Iłżecka J, Przywara S, Terlecki P, Grabarska AJ, Stepulak A, et al. Serum neuron-specific enolase as a marker of brain ischemia-reperfusion injury in patients undergoing carotid endarterectomy. Acta Clin Croat. 2016 [cited 2018 Dec 9];57983. Available from: https://hrcak.srce.hr/index.php?show= clanak\&id_clanak_jezik=262239

81. Goksuluk H, Gulec S, Ozcan OU, Gerede M, Vurgun VK, Ozyuncu N, et al. Usefulness of neuron-specific enolase to detect silent neuronal ischemia after percutaneous coronary intervention. Am J Cardiol. 2016 [cited 2018 Dec 9];117:1917-1920. Available from: http://www.ncbi.nlm.nih.gov/pubmed/27134059.

82. Lu K, Xu X, Cui S, Wang F, Zhang B, Zhao Y. Serum neuron specific enolase level as a predictor of prognosis in acute ischemic stroke patients after intravenous thrombolysis. J Neurol Sci. 2015 [cited 2018 Dec 9];359:202-206. Available from: http:// www.ncbi.nlm.nih.gov/pubmed/26671113. 
83. Fahmi RM, Elsaid AF. Infarction size, interleukin-6, and their interaction are predictors of short-term stroke outcome in young Egyptian adults. J Stroke Cerebrovasc Dis. 2016 [cited 2018 Dec 9];25:2475-2481. Available from: http:// www.ncbi.nlm.nih.gov/pubmed/27402591.

84. Tarkowski E, Rosengren L, Blomstrand C, Wikkelsö C, Jensen C, Ekholm S, et al. Early intrathecal production of interleukin-6 predicts the size of brain lesion in stroke. Stroke. 1995 [cited 2018 Dec 9];26:1393-1398. Available from: http:// www.ncbi.nlm.nih.gov/pubmed/7631343.

85. Martinic-Popovic I, Simundic AM, Dukic L, Lovrencic-Huzjan A, Popovic A, Seric V, et al. The association of inflammatory markers with cerebral vasoreactivity and carotid atherosclerosis in transient ischaemic attack. Clin Biochem. 2014 [cited 2018 Dec 9];47:182-186. Available from: http:// www.ncbi.nlm.nih.gov/pubmed/25046654.

86. Miwa K, Tanaka M, Okazaki S, Furukado S, Sakaguchi M, Mochizuki H, et al. Association between interleukin-6 levels and first-ever cerebrovascular events in patients with vascular risk factors. Arterioscler Thromb Vasc Biol. 2013 [cited 2018 Dec 9];33: 400-405. Available from: http://www.ncbi.nlm.nih.gov/pubmed/ 23175672 .

87. Oto J, Suzue A, Inui D, Fukuta Y, Hosotsubo K, Torii M, et al. Plasma proinflammatory and anti-inflammatory cytokine and catecholamine concentrations as predictors of neurological outcome in acute stroke patients. J Anesth. 2008 [cited 2019 Aug 28];22: 207-212. Available from: http://link.springer.com/10.1007/ s00540-008-0639-x

88. Diao ZY, Wang CL, Qi HS, Jia GY, Yan CZ. Significance of decreased serum interleukin-10 levels in the progression of cerebral infarction. Clin Exp Med. 2016 [cited 2018 Dec 9];16:203211. Available from: http://www.ncbi.nlm.nih.gov/pubmed/ 25847570.

89. Wang L, Wei C, Deng L, Wang Z, Song M, Xiong Y, et al. The accuracy of serum matrix metalloproteinase-9 for predicting hemorrhagic transformation after acute ischemic stroke: a systematic review and meta-analysis. J Stroke Cerebrovasc Dis. 2018 [cited 2018 Dec 9];27:1653-1665. Available from: http:// www.ncbi.nlm.nih.gov/pubmed/29598905.

90. Choi J Il, Ha SK, Lim DJ, Kim SD, Kim SH. S100ß, matrix metalloproteinase-9, D-dimer, and heat shock protein 70 are serologic biomarkers of acute cerebral infarction in a mouse model of transient MCA occlusion. J Korean Neurosurg Soc. 2018 [cited 2018 Dec 9];61:548-558. Available from: http:// www.ncbi.nlm.nih.gov/pubmed/29724092.

91. Zhong C, Yang J, Xu T, Xu T, Peng Y, Wang A, et al. Serum matrix metalloproteinase-9 levels and prognosis of acute ischemic stroke. Neurology. 2017 [cited 2018 Dec 9];89:805-812. Available from: http://www.ncbi.nlm.nih.gov/pubmed/28747453.

92. Castellanos M, Leira R, Serena J, Pumar JM, Lizasoain I, Castillo $\mathrm{J}$, et al. Plasma metalloproteinase-9 concentration predicts hemorrhagic transformation in acute ischemic stroke. Stroke. 2003 [cited 2019 Aug 28];34:40-46. Available from: http:// www.ncbi.nlm.nih.gov/pubmed/12511748.

93. Montaner J, Molina CA, Monasterio J, Abilleira S, Arenillas JF, Ribó M, et al. Matrix metalloproteinase-9 pretreatment level predicts intracranial hemorrhagic complications after thrombolysis in human stroke. Circulation. 2003 [cited 2019 Aug 28];107:598603. Available from: http://www.ncbi.nlm.nih.gov/pubmed/ 12566373.

94. Montaner J, Fernández-Cadenas I, Molina CA, Monasterio J, Arenillas JF, Ribó M, et al. Safety profile of tissue plasminogen activator treatment among stroke patients carrying a common polymorphism $(\mathrm{C}-1562 \mathrm{~T})$ in the promoter region of the matrix metalloproteinase-9 gene. Stroke. 2003 Lippincott Williams \& Wilkins; [cited 2019 Aug 28];34:2851-5. Available from:
https://www.ahajournals.org/doi/10.1161/01.STR.0000098648. $54429.1 \mathrm{C}$

95. Castellanos M, Sobrino T, Millán M, García M, Arenillas J, Nombela F, et al. Serum cellular fibronectin and matrix metalloproteinase-9 as screening biomarkers for the prediction of parenchymal hematoma after thrombolytic therapy in acute ischemic stroke: a multicenter confirmatory study. Stroke. 2007 [cited 2019 Aug 28];38:1855-1859. Available from: http:// www.ncbi.nlm.nih.gov/pubmed/17478737.

96. Abdelnaseer MM, Elfauomy NM, Esmail EH, Kamal MM, Elsawy EH. Matrix metalloproteinase-9 and recovery of acute ischemic stroke. J Stroke Cerebrovasc Dis. 2017 [cited 2018 Dec 9];26:733-740. Available from: http:// www.ncbi.nlm.nih.gov/pubmed/28063771.

97. Liu T, Clark RK, McDonnell PC, Young PR, White RF, Barone $\mathrm{FC}$, et al. Tumor necrosis factor- $\alpha$ expression in ischemic neurons. Stroke. 1994 [cited 2018 Dec 9];25:1481-1488. Available from: http://www.ncbi.nlm.nih.gov/pubmed/8023366.

98. Kim CR, Kim JH, Park HYL, Park CK. Ischemia reperfusion injury triggers TNF $\alpha$ induced-necroptosis in rat retina. Curr Eye Res. 2017 [cited 2018 Dec 9];42:771-779. Available from: http:// www.ncbi.nlm.nih.gov/pubmed/27732109.

99. Wang K, Ye L, Lu H, Chen H, Zhang Y, Huang Y, et al. TNF- $\alpha$ promotes extracellular vesicle release in mouse astrocytes through glutaminase. J Neuroinflammation. BioMed Central; 2017 [cited 2018 Dec 9];14:87. Available from: http://www.ncbi.nlm.nih.gov/ pubmed/28427419.

100. Šumanović-G Lamuzina D, Čulo F, Čulo MI, Konjevoda P, Raguž MJ. A comparison of blood and cerebrospinal fluid cytokines (IL$1 \beta$, IL-6, IL-18, TNF- $\alpha$ ) in neonates with perinatal hypoxia. Bosn J Basic Med Sci. 2017 Association of Basic Medical Sciences of Federation of Bosnia and Herzegovina; [cited 2018 Dec 9];17: 203-10. Available from: http://www.ncbi.nlm.nih.gov/pubmed/ 28418828.

101. Lin C, Tang X, Shi Z, Zhang L, Yan D, Niu C, et al. Serum tumor necrosis factor $\alpha$ levels are associated with new ischemic brain lesions after carotid artery stenting. J Vasc Surg. 2018 [cited 2018 Dec 9];68:771-778. Available from: http:// www.ncbi.nlm.nih.gov/pubmed/29567026.

102. Tuttolomondo A, Pecoraro R, Di Raimondo D, Di Sciacca R, Canino B, Arnao V, et al. Immune-inflammatory markers and arterial stiffness indexes in subjects with acute ischemic stroke with and without metabolic syndrome. Diabetol Metab Syndr. 2014 BioMed Central; [cited 2019 Aug 28];6:28. Available from: http://www.ncbi.nlm.nih.gov/pubmed/24571954.

103. Tuttolomondo A, Di Raimondo D, Pecoraro R, Arnao V, Pinto A, Licata G. Inflammation in ischemic stroke subtypes. Curr Pharm Des. 2012 [cited 2019 Aug 28];18:4289-4310. Available from: http://www.ncbi.nlm.nih.gov/pubmed/22390641.

104. Licata G, Tuttolomondo A, Corrao S, Di Raimondo D, Fernandez $\mathrm{P}$, Caruso $\mathrm{C}$, et al. Immunoinflammatory activation during the acute phase of lacunar and non-lacunar ischemic stroke: association with time of onset and diabetic state. Int J Immunopathol Pharmacol. 2006 [cited 2019 Aug 28];19:639-646. Available from: http://www.ncbi.nlm.nih.gov/pubmed/17026849.

105. Bongers TN, De Maat MPM, Van Goor MLPJ, Bhagwanbali V, Van Vliet HHDM, García EBG, et al. High von Willebrand factor levels increase the risk of first ischemic stroke: influence of ADAMTS13, inflammation, and genetic variability. Stroke. 2006 [cited 2018 Dec 9];37:2672-2677. Available from: http:// www.ncbi.nlm.nih.gov/pubmed/16990571.

106. Tobin WO, Kinsella JA, Kavanagh GF, O’Donnell JS, McGrath RT, Tierney S, et al. Profile of von Willebrand factor antigen and von Willebrand factor propeptide in an overall TIA and ischaemic stroke population and amongst subtypes. J Neurol Sci. 2017 [cited 
2018 Dec 9];375:404-410. Available from: http:// www.ncbi.nlm.nih.gov/pubmed/28320178.

107. Hanson E, Jood K, Karlsson S, Nilsson S, Blomstrand C, Jern C. Plasma levels of von Willebrand factor in the etiologic subtypes of ischemic stroke. J Thromb Haemost. 2011 [cited 2018 Dec 9];9: 275-281. Available from: http://www.ncbi.nlm.nih.gov/pubmed/ 21054779.

108. Menih M, Križmarić M, Hojs Fabjan T. Clinical role of von Willebrand factor in acute ischemic stroke. Wien Klin Wochenschr. 2017 [cited 2018 Dec 9];129:491-496. Available from: http://www.ncbi.nlm.nih.gov/pubmed/28409234.

109. Liu X, Liu J, Zhao S, Zhang H, Cai W, Cai M, et al. Interleukin-4 is essential for microglia/macrophage M2 polarization and longterm recovery after cerebral ischemia. Stroke. 2016 [cited 2018 Dec 9];47:498-504. Available from: http:// www.ncbi.nlm.nih.gov/pubmed/26732561.

110. Zhao X, Wang H, Sun G, Zhang J, Edwards NJ, Aronowski J. Neuronal interleukin-4 as a modulator of microglial pathways and ischemic brain damage. J Neurosci. 2015 [cited 2018 Dec 9];35: 11281-11291. Available from: http://www.ncbi.nlm.nih.gov/ pubmed/26269636.

111. García-Berrocoso T, Giralt D, Bustamante A, Llombart V, Rubiera $\mathrm{M}$, Penalba A, et al. Role of beta-defensin 2 and interleukin-4 receptor as stroke outcome biomarkers. J Neurochem. 2014 [cited 2018 Dec 9];129:463-472. Available from: http:// www.ncbi.nlm.nih.gov/pubmed/24386991.

112. Protti GG, Gagliardi RJ, Forte WCN, Sprovieri SRS. Interleukin10 may protect against progressing injury during the acute phase of ischemic stroke. Arq Neuropsiquiatr. 2013 [cited 2018 Dec 9];71:846-51. Available from: http://www.ncbi.nlm.nih.gov/ pubmed/24394869.

113. Vila N, Castillo J, Dávalos A, Esteve A, Planas AM, Chamorro A. Levels of anti-inflammatory cytokines and neurological worsening in acute ischemic stroke. Stroke. 2003 [cited 2018 Dec 9];34: 671-675. Available from: http://www.ncbi.nlm.nih.gov/pubmed/ 12624290.

114. Chang LT, Yuen CM, Liou CW, Lu CH, Chang WN, Youssef AA, et al. Link between interleukin-10 level and outcome after ischemic stroke. Neuroimmunomodulation. 2010 [cited 2018 Dec 9];17:223-228. Available from: http:// www.ncbi.nlm.nih.gov/pubmed/20203528.

115. Jiang Y, Wei N, Zhu J, Lu T, Chen Z, Xu G, et al. Effects of brainderived neurotrophic factor on local inflammation in experimental stroke of rat. Mediators Inflamm. 2010 Hindawi; [cited 2018 Dec 12];2010:372423. Available from: http:// www.ncbi.nlm.nih.gov/pubmed/21490702.

116. Pikula A, Beiser AS, Chen TC, Preis SR, Vorgias D, Decarli C, et al. Serum brain-derived neurotrophic factor and vascular endothelial growth factor levels are associated with risk of stroke and vascular brain injury framingham study. Stroke. 2013 [cited 2018 Dec 10];44:2768-2775. Available from: http:// www.ncbi.nlm.nih.gov/pubmed/23929745.

117. Stanne TM, Aberg ND, Nilsson S, Jood K, Blomstrand C, Andreasson U, et al. Low circulating acute brain-derived neurotrophic factor levels are associated with poor long-term functional outcome after ischemic stroke. Stroke. 2016 [cited 2018 Dec 12];47:1943-1945. Available from: http:// www.ncbi.nlm.nih.gov/pubmed/27301948.

118. Lu H, Liu X, Zhang N, Zhu X, Liang H, Sun L, et al. Neuroprotective effects of brain-derived neurotrophic factor and Noggin-modified bone mesenchymal stem cells in focal cerebral ischemia in rats. J Stroke Cerebrovasc Dis. 2016 [cited 2018 Dec 12];25:410-418. Available from: http:// www.ncbi.nlm.nih.gov/pubmed/26654668.

119. Chen HH, Zhang N, Li WY, Fang MR, Zhang H, Fang YS, et al. Overexpression of brain-derived neurotrophic factor in the hippocampus protects against post-stroke depression. Neural Regen Res. 2015 [cited 2018 Dec 12];10:1427-1432. Available from: http://www.ncbi.nlm.nih.gov/pubmed/26604903.

120. Zhang ZH, Wu LN, Song JG, Li WQ. Correlations between cognitive impairment and brain-derived neurotrophic factor expression in the hippocampus of post-stroke depression rats. Mol Med Rep. 2012 [cited 2018 Dec 12];6:889-893. Available from: http:// www.ncbi.nlm.nih.gov/pubmed/22842820.

121. Wang Y, Chang CF, Morales M, Chiang YH, Hoffer J. Protective effects of glial cell line-derived neurotrophic factor in ischemic brain injury. Ann N Y Acad Sci. 2002 [cited 2018 Dec 12]. p. 423-37. Available from: http://www.ncbi.nlm.nih.gov/pubmed/ 12076993.

122. Narantuya D, Nagai A, Abdullah M, Masuda J, Kobayashi S, Yamaguchi S, et al. Human microglia transplanted in rat focal ischemia brain induce neuroprotection and behavioral improvement. Gendelman HE, editor. PLoS One. 2010 Public Library of Science; [cited 2018 Dec 12];5:e11746. Available from: http://dx. plos.org/10.1371/journal.pone.0011746

123. Ou Y, Yu S, Kaneko Y, Tajiri N, Bae EC, Chheda SH, et al. Intravenous infusion of GDNF gene-modified human umbilical cord blood CD34+ cells protects against cerebral ischemic injury in spontaneously hypertensive rats. Brain Res. 2010 [cited 2018 Dec 12];1366:217-225. Available from: http:// www.ncbi.nlm.nih.gov/pubmed/20888805.

124. Miyazaki H, Nagashima K, Okuma Y, Nomura Y. Expression of glial cell line-derived neurotrophic factor induced by transient forebrain ischemia in rats. Brain Res. 2001 [cited 2018 Dec 12];922:165-172. Available from: http:// www.ncbi.nlm.nih.gov/pubmed/11743946.

125. Liu Y, Wang S, Luo S, Li Z, Liang F, Zhu Y, et al. Intravenous PEP-1-GDNF is protective after focal cerebral ischemia in rats. Neurosci Lett. 2016 [cited 2018 Dec 12];617:150-155. Available from: http://www.ncbi.nlm.nih.gov/pubmed/26876444.

126. Guégan C, Ceballos-Picot I, Nicole A, Kato H, Onténiente B, Sola B. Recruitment of several neuroprotective pathways after permanent focal ischemia in mice. Exp Neurol. 1998 Academic Press; [cited 2018 Dec 12];154:371-80. Available from: https://www. sciencedirect.com/science/article/pii/S0014488698969138

127. Wang Y, Cao M, Liu A, Di W, Zhao F, Tian Y, et al. Changes of inflammatory cytokines and neurotrophins emphasized their roles in hypoxic-ischemic brain damage. Int J Neurosci. 2013 [cited 2018 Dec 12];123:191-195. Available from: http:// www.ncbi.nlm.nih.gov/pubmed/23110519.

128. Zhang ZH, Xi GM, Li WC, Ling HY, Qu P, Fang XB. CyclicAMP response element binding protein and tau are involved in the neuroprotective mechanisms of nerve growth factor during focal cerebral ischemia/reperfusion in rats. J Clin Neurosci. 2010 [cited 2018 Dec 12];17:353-356. Available from: http:// www.ncbi.nlm.nih.gov/pubmed/20071183.

129. Ke XJ, Zhang JJ. Changes in HIF-1 $\alpha$, VEGF, NGF and BDNF levels in cerebrospinal fluid and their relationship with cognitive impairment in patients with cerebral infarction. J Huazhong Univ Sci Technol - Med Sci. 2013 Huazhong University of Science and Technology; [cited 2018 Dec 12];33:433-7. Available from: http://ink.springer.com/10.1007/s11596-013-1137-4

130. Lietzau G, Kowiański P, Karwacki Z, Dziewiątkowski J, Witkowska M, Sidor-Kaczmarek J, et al. The molecular mechanisms of cell death in the course of transient ischemia are differentiated in evolutionary distinguished brain structures. Metab Brain Dis. 2009 [cited 2018 Dec 9];24:507-523. Available from: http://www.ncbi.nlm.nih.gov/pubmed/19693659.

131. Herrmann M, Vos P, Wunderlich MT, De Bruijn CHMM, Lamers KJB. Release of glial tissue-specific proteins after acute stroke: a comparative analysis of serum concentrations of protein S-100B and glial fibrillary acidic protein. Stroke. 2000 [cited 2018 
Dec 9];31:2670-2677. Available from: https://www.ahajournals. org/doi/10.1161/01.STR.31.11.2670

132. Missler U, Wiesmann M, Wittmann G, Magerkurth O, Hagenström $H$. Measurement of glial fibrillary acidic protein in human blood: analytical method and preliminary clinical results. Clin Chem. 1999 [cited 2018 Dec 9];45:138-141. Available from: http://www.ncbi.nlm.nih.gov/pubmed/9895354.

133. Fang C, Lou B, Zhou J, Zhong R, Wang R, Zang X, et al. Blood biomarkers in ischemic stroke: role of biomarkers in differentiation of clinical phenotype. Eur J Inflamm. 2018 SAGE PublicationsSage UK: London, England; [cited 2019 Aug 28];16:205873921878005. Available from: http://journals. sagepub.com/doi/10.1177/2058739218780058

134. Kleindienst A, McGinn MJ, Harvey HB, Colello RJ, Hamm RJ, Bullock MR. Enhanced Hippocampal neurogenesis by intraventricular S100B infusion is associated with improved cognitive recovery after traumatic brain injury. J Neurotrauma. 2005 [cited 2018 Dec 9];22:645-655. Available from: http:// www.ncbi.nlm.nih.gov/pubmed/15941374.

135. Hu J, Castets F, Guevara JL, Van Eldiki LJ. S100ß stimulates inducible nitric oxide synthase activity and mRNA levels in rat cortical astrocytes. J Biol Chem. American Society for Biochemistry and Molecular Biology; 1996 [cited 2018 Dec 9];271:2543-7. Available from: http:// www.ncbi.nlm.nih.gov/pubmed/8576219.

136. Koppal T, Lam AGM, Guo L, Van Eldik LJ. S100B proteins that lack one or both cysteine residues can induce inflammatory responses in astrocytes and microglia. Neurochem Int. 2001 [cited 2018 Dec 9];39:401-407. Available from: http:// www.ncbi.nlm.nih.gov/pubmed/11578775.

137. Büttner T, Weyers S, Postert T, Sprengelmeyer R, Kuhn W. S-100 protein: serum marker of focal brain damage after ischemic territorial MCA infarction. Stroke. 1997 [cited 2018 Dec 9];28:19611965. Available from: http://www.ncbi.nlm.nih.gov/pubmed/ 9341704.

138. Missler U, Wiesmann M, Friedrich C, Kaps M. S-100 protein and neuron-specific enolase concentrations in blood as indicators of infarction volume and prognosis in acute ischemic stroke. Stroke. 1997 [cited 2018 Dec 9];28:1956-1960. Available from: http:// www.ncbi.nlm.nih.gov/pubmed/9341703.

139. Fassbender K, Schmidt R, Schreiner A, Fatar M, Mühlhauser F, Daffertshofer $\mathrm{M}$, et al. Leakage of brain-originated proteins in peripheral blood: temporal profile and diagnostic value in early ischemic stroke. J Neurol Sci. 1997 [cited 2018 Dec 9];148:101105. Available from: http://www.ncbi.nlm.nih.gov/pubmed/ 9125396.

140. Tang G, Yang GY. Aquaporin-4: a potential therapeutic target for cerebral edema. Int. J. Mol. Sci. 2016 [cited 2018 Dec 9]. p. 1413. Available from: http://www.ncbi.nlm.nih.gov/pubmed/27690011.

141. Friedman B, Schachtrup C, Tsai PS, Shih AY, Akassoglou K, Kleinfeld D, et al. Acute vascular disruption and aquaporin 4 loss after atroke. Stroke. 2009 [cited 2019 Aug 27];40:2182-2190. Available from: http://www.ncbi.nlm.nih.gov/pubmed/19372455.

142. Zhou J, Kong H, Hua X, Xiao M, Ding J, Hu G. Altered bloodbrain barrier integrity in adult aquaporin-4 knockout mice. Neuroreport. 2008 [cited 2019 Aug 27];19:1-5. Available from: http://www.ncbi.nlm.nih.gov/pubmed/18281883.

143. Nakada T. The molecular mechanisms of neural flow coupling: a new concept. J Neuroimaging. 2015 [cited 2019 Aug 27];25:861865. Available from: http://www.ncbi.nlm.nih.gov/pubmed/ 25704766.

144. Igarashi H, Tsujita M, Suzuki Y, Kwee IL, Nakada T. Inhibition of aquaporin-4 significantly increases regional cerebral blood flow. Neuroreport. 2013 [cited 2019 Aug 27];24:324-328. Available from: http://www.ncbi.nlm.nih.gov/pubmed/23462267.
145. Nito C, Kamada H, Endo H, Narasimhan P, Lee Y-S, Chan PH. Involvement of mitogen-activated protein kinase pathways in expression of the water channel protein aquaporin- 4 after ischemia in rat cortical astrocytes. J Neurotrauma. 2012 Mary Ann Liebert, Inc.; [cited 2018 Dec 9];29:2404-12. Available from: http:// www.ncbi.nlm.nih.gov/pubmed/22676888.

146. Veerkamp JH, Zimmerman AW. Fatty acid-binding proteins of nervous tissue. J Mol Neurosci. 2001 [cited 2018 Dec 9]. p. 133-42. Available from: http://www.ncbi.nlm.nih.gov/pubmed/ 11478368 .

147. Kirsch J. Glycinergic transmission. Cell Tissue Res. 2006 [cited 2019 Mar 5]. p. 535-40. Available from: http:// www.ncbi.nlm.nih.gov/pubmed/16807723.

148. Głodzik-Sobańska L, Słowik A, Kozub J, Sobiecka B, Urbanik A, Szczudlik A. GABA in ischemic stroke. Proton magnetic resonance study. Med Sci Monit. 2004 [cited 2019 Aug 28];10 Suppl 3:88-93. Available from: http://www.ncbi.nlm.nih.gov/ pubmed/16538207.

149. Sienkiewicz-Jarosz H, Gałecka-Walska M, Bidziński A, Turzyńska D, Sobolewska A, Lipska B, et al. Predictive value of selected biochemical markers of brain damage for functional outcome in ischaemic stroke patients. Neurol Neurochir Pol. 2009 [cited 2019 Aug 28];43:126-133. Available from: https://www. semanticscholar.org/paper/Predictive-value-of-selectedbiochemical-markers-of-Sienkiewicz-Jarosz-Gałecka-Wolska/ 2cdb6a45a3ed69cebf5ccf1c2442ef23b4cedcd2

150. Shuaib A, Ijaz MS, Miyashita H, Hussain S, Kanthan R. GABA and glutamate levels in the substantia nigra reticulata following repetitive cerebral ischemia in gerbils. Exp Neurol. 1997 [cited 2019 Aug 28];147:311-315. Available from: http:// www.ncbi.nlm.nih.gov/pubmed/9344556.

151. Clarkson AN, Huang BS, MacIsaac SE, Mody I, Carmichael ST. Reducing excessive GABA-mediated tonic inhibition promotes functional recovery after stroke. Nature. 2010 [cited 2019 Aug 28];468:305-309. Available from: http:// www.ncbi.nlm.nih.gov/pubmed/21048709.

152. Schmidt D, Loscher W. Plasma and cerebrospinal fluid $\gamma$ aminobutyric acid in neurological disorders. J Neurol Neurosurg Psychiatry. 1982 BMJ Publishing Group; [cited 2019 Aug 28];45: 931-5. Available from: http://www.ncbi.nlm.nih.gov/pubmed/ 7143013.

153. Mayor D, Tymianski M. Neurotransmitters in the mediation of cerebral ischemic injury. Neuropharmacology. 2018 [cited 2019 Aug 28]. p. 178-88. Available from: http:// www.ncbi.nlm.nih.gov/pubmed/29203179.

154. Benke D, Balakrishnan K, Zemoura K. Regulation of cell surface GABAB receptors: contribution to synaptic plasticity in neurological diseases. Adv Pharmacol. 2015 [cited 2019 Aug 28]. p. 4170. Available from: http://www.ncbi.nlm.nih.gov/pubmed/ 25637437.

155. Huang L, Li Q, Wen R, Yu Z, Li N, Ma L, et al. Rho-kinase inhibitor prevents acute injury against transient focal cerebral ischemia by enhancing the expression and function of GABA receptors in rats. Eur J Pharmacol. 2017 [cited 2019 Aug 28];797: 134-142. Available from: http://www.ncbi.nlm.nih.gov/pubmed/ 28109911

156. Costa C, Leone G, Saulle E, Pisani F, Bernardi G, Calabresi P. Coactivation of GABAA and GABAB Receptor Results in Neuroprotection during In Vitro Ischemia. Stroke. 2004 [cited 2019 Aug 28];35:596-600. Available from: http:// www.ncbi.nlm.nih.gov/pubmed/14726544.

157. Mele M, Costa RO, Duarte CB. Alterations in GABAA-receptor trafficking and synaptic dysfunction in brain disorders. Front Cell Neurosci. Frontiers; 2019 [cited 2019 Aug 28];13:77. Available from: https://www.frontiersin.org/article/10.3389/fncel.2019. 00077/full 
158. Mele M, Ribeiro L, Inácio AR, Wieloch T, Duarte CB. GABAA receptor dephosphorylation followed by internalization is coupled to neuronal death in in vitro ischemia. Neurobiol Dis. 2014 [cited 2019 Aug 28];65:220-232. Available from: http:// www.ncbi.nlm.nih.gov/pubmed/24513087.

159. Wang X, Shimizu-Sasamata M, Moskowitz MA, Newcomb R, Lo EH. Profiles of glutamate and GABA efflux in core versus peripheral zones of focal cerebral ischemia in mice. Neurosci Lett. 2001 [cited 2019 Aug 28];313:121-4. Available from: http:// www.ncbi.nlm.nih.gov/pubmed/11682142.

160. Miya K, Inoue R, Takata Y, Abe M, Natsume R, Sakimura K, et al. Serine racemase is predominantly localized in neurons in mouse brain. J Comp Neurol. 2008 [cited 2018 Dec 9];510:641-654. Available from: http://www.ncbi.nlm.nih.gov/pubmed/18698599.

161. Li S, Uno Y, Rudolph U, Cobb J, Liu J, Anderson T, et al. Astrocytes in primary cultures express serine racemase, synthesize D-serine and acquire A1 reactive astrocyte features. Biochem Pharmacol. 2018 [cited 2018 Dec 9];151:245-251. Available from: http://www.ncbi.nlm.nih.gov/pubmed/29305854.

162. Jayakumar AR, Norenberg MD. Glutamine synthetase: role in neurological disorders. Adv Neurobiol [Internet]. 2016 [cited 2018 Dec 9]. p. 327-50. Available from: http:// www.ncbi.nlm.nih.gov/pubmed/27885636.

163. Snyder SH, Ferris CD. Novel neurotransmitters and their neuropsychiatric relevance. Am. J. Psychiatry. 2000 [cited 2018 Dec 9]. p. 1738-51. Available from: http://www.ncbi.nlm.nih.gov/ pubmed/11058466.

164. Yoshikawa M, Takayasu N, Hashimoto A, Sato Y, Tamaki R, Tsukamoto $\mathrm{H}$, et al. The serine racemase mRNA is predominantly expressed in rat brain neurons. Arch Histol Cytol. 2007 [cited 2018 Dec 9];70:127-134. Available from: http:// www.ncbi.nlm.nih.gov/pubmed/17827670.

165. Cunningham RT, Watt M, Winder J, McKinstry S, Lawson JT, Johnston CF, et al. Serum neurone-specific enolase as an indicator of stroke volume. Eur J Clin Invest. 1996 [cited 2018 Dec 9];26: 298-303. Available from: http://www.ncbi.nlm.nih.gov/pubmed/ 8732487.

166. Hu Y, Meng R, Zhang X, Guo L, Li S, Wu Y, et al. Serum neuron specific enolase may be a marker to predict the severity and outcome of cerebral venous thrombosis. J Neurol. 2018 [cited 2018 Dec 9];265:46-51. Available from: http://www.ncbi.nlm.nih.gov/ pubmed/29128928.

167. Stammet P, Collignon O, Hassager C, Wise MP, Hovdenes J, Åneman A, et al. Neuron-specific enolase as a predictor of death or poor neurological outcome after out-of-hospital cardiac arrest and targeted temperature management at $33^{\circ} \mathrm{C}$ and $36^{\circ} \mathrm{C} . \mathrm{J} \mathrm{Am}$ Coll Cardiol. 2015 [cited 2018 Dec 9];65:2104-2114. Available from: http://www.ncbi.nlm.nih.gov/pubmed/25975474.

168. Fassbender K, Rossol S, Kammer T, Daffertshofer M, Wirth S, Dollman M, et al. Proinflammatory cytokines in serum of patients with acute cerebral ischemia: kinetics of secretion and relation to the extent of brain damage and outcome of disease. J Neurol Sci. 1994 [cited 2018 Dec 9];122:135-139. Available from: http:/ www.ncbi.nlm.nih.gov/pubmed/8021695.

169. Perini F, Morra M, Alecci M, Galloni E, Marchi M, Toso V. Temporal profile of serum anti-inflammatory and proinflammatory interleukins in acute ischemic stroke patients. Neurol Sci. 2001 [cited 2018 Dec 9];22:289-296. Available from: http://www.ncbi.nlm.nih.gov/pubmed/11808851.

170. Nakamachi T, Tsuchida M, Kagami N, Yofu S, Wada Y, Hori M, et al. IL-6 and PACAP receptor expression and localization after global brain ischemia in mice. J Mol Neurosci . 2012 [cited 2018 Dec 9];48:518-525. Available from: http:// www.ncbi.nlm.nih.gov/pubmed/22669509.

171. Lambertsen KL, Biber K, Finsen B. Inflammatory cytokines in experimental and human stroke. J. Cereb. Blood Flow Metab.
2012 [cited 2018 Dec 9]. p. 1677-98. Available from: http:// www.ncbi.nlm.nih.gov/pubmed/22739623.

172. Pusch G, Debrabant B, Molnar T, Feher G, Papp V, Banati M, et al. Early dynamics of P-selectin and interleukin 6 predicts outcomes in ischemic stroke. J Stroke Cerebrovasc Dis. 2015 [cited 2018 Dec 9];24:1938-1947. Available from: http:// www.ncbi.nlm.nih.gov/pubmed/26051664.

173. Muroi C, Hugelshofer M, Seule M, Tastan I, Fujioka M, Mishima $\mathrm{K}$, et al. Correlation among systemic inflammatory parameter, occurrence of delayed neurological deficits, and outcome after aneurysmal subarachnoid hemorrhage. Neurosurgery. 2013 [cited 2019 Aug 28];72:367-375. Available from: http:// www.ncbi.nlm.nih.gov/pubmed/23208059.

174. Osuka K, Suzuki Y, Tanazawa T, Hattori K, Yamamoto N, Takayasu M, et al. Interleukin-6 and development of vasospasm after subarachnoid haemorrhage. Acta Neurochir (Wien). 1998 [cited 2019 Aug 28];140:943-951. Available from: http:// www.ncbi.nlm.nih.gov/pubmed/9842432.

175. Ferrarese C, Mascarucci P, Zoia C, Cavarretta R, Frigo M, Begni $\mathrm{B}$, et al. Increased cytokine release from peripheral blood cells after acute stroke. J Cereb Blood Flow Metab. 1999 [cited 2019 Aug 28];19:1004-1009. Available from: http:// www.ncbi.nlm.nih.gov/pubmed/10478652.

176. Han YH. Association between IL6 polymorphism and risk of cerebral infarction. Genet Mol Res. 2015 [cited 2018 Dec 9];14: 16438-16443. Available from: http://www.ncbi.nlm.nih.gov/ pubmed/26662441.

177. Kumar P, Kumar A, Sagar R, Misra S, Faruq M, Suroliya V, et al. Association between interleukin-6 (G174C and C572G) promoter gene polymorphisms and risk of ischemic stroke in North Indian population: a case-control study. Neurol Res. 2016 [cited 2018 Dec 9];38:69-74. Available from: http://www.ncbi.nlm.nih.gov/ pubmed/26883819.

178. Kumar P, Yadav AK, Kumar A, Sagar R, Pandit AK, Prasad K. Association between interleukin-6 (G174C and G572C) promoter gene polymorphisms and risk of ischaemic stroke: a meta-analysis. Ann Neurosci. 2015 Karger Publishers; [cited 2018 Dec 9];22: 61-9. Available from: http://www.ncbi.nlm.nih.gov/pubmed/ 26130909.

179. Ramos-Fernandez M, Bellolio MF, Stead LG. Matrix metalloproteinase-9 as a marker for acute ischemic stroke: a systematic review. J Stroke Cerebrovasc Dis. 2011 [cited 2019 Aug 28];20:47-54. Available from: http:// www.ncbi.nlm.nih.gov/pubmed/21044610.

180. Montaner J, Alvarez-Sabín J, Molina CA, Anglés A, Abilleira S, Arenillas J, et al. Matrix metalloproteinase expression is related to hemorrhagic transformation after cardioembolic stroke. Stroke. 2001 [cited 2019 Aug 28];32:2762-2767. Available from: http:// www.ncbi.nlm.nih.gov/pubmed/11739970.

181. Akpinar A, Ucler N, Erdogan U, Baydin SS, Gungor A, Tugcu B. Measuring serum matrix metalloproteinase-9 levels in peripheral blood after subarachnoid hemorrhage to predict cerebral vasospasm. Springerplus. 2016 [cited 2018 Dec 9];5:1153. Available from: http:/www.ncbi.nlm.nih.gov/pubmed/27504251.

182. Triglia T, Mezzapesa A, Martin JC, Verdier M, Lagier D, Dufour $\mathrm{H}$, et al. Early matrix metalloproteinase- 9 concentration in the first $48 \mathrm{~h}$ after aneurysmal subarachnoid haemorrhage predicts delayed cerebral ischaemia. Eur J Anaesthesiol. 2016 [cited 2018 Dec 9];33:662-669. Available from: http:// www.ncbi.nlm.nih.gov/pubmed/27355865.

183. Misra S, Talwar P, Kumar A, Kumar P, Sagar R, Vibha D, et al. Association between matrix metalloproteinase family gene polymorphisms and risk of ischemic stroke: a systematic review and meta-analysis of 29 studies. Gene. 2018 [cited 2018 Dec 9]. p. 180-94. Available from: http://www.ncbi.nlm.nih.gov/pubmed/ 29906531. 
184. Zhao JH, Xu YM, Xing HX, Su LL, Tao SB, Tian XJ, et al. Associations between matrix metalloproteinase gene polymorphisms and the development of cerebral infarction. Genet Mol Res. 2015 [cited 2018 Dec 9];14:19418-19424. Available from: http://www.ncbi.nlm.nih.gov/pubmed/26782596.

185. Liddelow SA, Guttenplan KA, Clarke LE, Bennett FC, Bohlen CJ, Schirmer L, et al. Neurotoxic reactive astrocytes are induced by activated microglia. Nature. 2017 Nature Publishing Group; [cited 2018 Dec 9];541:481-7. Available from: http://www.nature.com/ articles/nature21029

186. Gabel S, Koncina E, Dorban G, Heurtaux T, Birck C, Glaab E, et al. Inflammation promotes a conversion of astrocytes into neural progenitor cells via NF-KB activation. Mol Neurobiol. 2016 [cited 2018 Dec 9];53:5041-5055. Available from: http:// www.ncbi.nlm.nih.gov/pubmed/26381429.

187. Kim M, Jung K, Kim IS, Lee IS, Ko Y, Shin JE, et al. TNF- $\alpha$ induces human neural progenitor cell survival after oxygenglucose deprivation by activating the NF-kB pathway. Exp Mol Med. 2018 [cited 2018 Dec 9];50:14. Available from: http:// www.ncbi.nlm.nih.gov/pubmed/29622770.

188. Salama H, Hammad E. Risk Association between TNF- $\alpha-308$ $\mathrm{G}>\mathrm{A}$ and IL-6-174 G/C polymorphisms and recurrent transient ischemic attacks. Egypt J Immunol. 2015 [cited 2018 Dec 9];22: 49-56. Available from: http://www.ncbi.nlm.nih.gov/pubmed/ 28502144.

189. Gu L, Wu G, Su L, Yan Y, Liang B, Tan J, et al. TNF-a (-238G/A and-308G/A) gene polymorphisms may not contribute to the risk of ischemic stroke. Int J Neurosci. 2016 Taylor \& FrancisNew York; [cited 2019 Mar 5];126:219-26. Available from: http:// www.tandfonline.com/doi/full/10.3109/00207454.2015.1010200

190. Sonneveld MAH, De Maat MPM, Leebeek FWG. Von Willebrand factor and ADAMTS13 in arterial thrombosis: a systematic review and meta-analysis. Blood Rev. 2014 [cited 2018 Dec 9]. p. 16778. Available from: http://www.ncbi.nlm.nih.gov/pubmed/ 24825749 .

191. Shi D, Xia T, Feng H, Cheng Q. Evaluating the diagnostic value of vWF: Ag, D-D and FDP in patients with acute cerebral infarction using ROC curves. Exp Ther Med. 2014 Spandidos Publications; [cited 2018 Dec 9];7:1573-7. Available from: http:// www.ncbi.nlm.nih.gov/pubmed/24926346.

192. Kraft P, Drechsler C, Gunreben I, Nieswandt B, Stoll G, Heuschmann PU, et al. Von Willebrand factor regulation in patients with acute and chronic cerebrovascular disease: a pilot, case-control study. Minnerup J, editor. PLoS One. 2014 Public Library of Science; [cited 2018 Dec 9];9:e99851. Available from: https://dx.plos.org/10.1371/journal.pone.0099851

193. Lively S, Hutchings S, Schlichter LC. Molecular and cellular responses to interleukin-4 treatment in a rat model of transient ischemia. J Neuropathol Exp Neurol. 2016 [cited 2018 Dec 9]. p. 1058-71. Available from: http://www.ncbi.nlm.nih.gov/pubmed/ 27634961.

194. Kim HM, Shin HY, Jeong HJ, An HJ, Kim NS, Chae HJ, et al. Reduced IL-2 but elevated IL-4, IL-6, and IgE serum levels in patients with cerebral infarction during the acute stage. J Mol Neurosci. 2000 [cited 2018 Dec 9];14:191-196. Available from: http://www.ncbi.nlm.nih.gov/pubmed/10984195.

195. Marousi SG, Ellul J, Antonacopoulou A, Gogos C, Papathanasopoulos P, Karakantza M. Functional polymorphisms of interleukin 4 and interleukin 10 may predict evolution and functional outcome of an ischaemic stroke. Eur J Neurol. 2011 [cited 2018 Dec 9];18:637-643. Available from: http:// www.ncbi.nlm.nih.gov/pubmed/20880001.

196. Zee RYL, Cook NR, Cheng S, Reynolds R, Erlich HA, Lindpaintner K, et al. Polymorphism in the P-selectin and interleukin-4 genes as determinants of stroke: a population-based, prospective genetic analysis. Hum Mol Genet. 2004 [cited 2018
Dec 9];13:389-396. Available from: http:// www.ncbi.nlm.nih.gov/pubmed/14681304.

197. Ledeboer A, Brevé JJP, Wierinckx A, Van Der Jagt S, Bristow AF, Leysen JE, et al. Expression and regulation of interleukin-10 and interleukin-10 receptor in rat astroglial and microglial cells. Eur J Neurosci. 2002 [cited 2018 Dec 9];16:1175-1185. Available from: http://www.ncbi.nlm.nih.gov/pubmed/12405978.

198. Norden DM, Fenn AM, Dugan A, Godbout JP. TGF $\beta$ produced by IL-10 redirected astrocytes attenuates microglial activation. Glia. 2014 [cited 2018 Dec 9];62:881-895. Available from: http://www.ncbi.nlm.nih.gov/pubmed/24616125.

199. Zhai QH, Futrell N, Chen FJ. Gene expression of IL-10 in relationship to TNF- $\alpha$, IL-1 $\beta$ and IL-2 in the rat brain following middle cerebral artery occlusion. J Neurol Sci. 1997 [cited 2018 Dec 9];152:119-124. Available from: http:// www.ncbi.nlm.nih.gov/pubmed/9415530.

200. He ML, Lv ZY, Shi X, Yang T, Zhang Y, Li TY, et al. Interleukin10 release from astrocytes suppresses neuronal apoptosis via the TLR2/NFKB pathway in a neonatal rat model of hypoxic-ischemic brain damage. J Neurochem. 2017 [cited 2018 Dec 9];142:920933. Available from: http://www.ncbi.nlm.nih.gov/pubmed/ 28700093.

201. Perez-Asensio FJ, Perpina U, Planas AM, Pozas E. Interleukin-10 regulates progenitor differentiation and modulates neurogenesis in adult brain. J Cell Sci. 2013 [cited 2018 Dec 9];126:4208-4219. Available from: http://www.ncbi.nlm.nih.gov/pubmed/23843621.

202. Ozkan A, Silan F, Uludag A, Degirmenci Y, Karaman HIO. Tumour necrosis factor alpha, interleukin 10 and interleukin 6 gene polymorphisms of ischemic stroke patients in south Marmara region of Turkey. Int J Clin Exp Pathol. 2015 [cited 2018 Dec 9];8:13500-13504. Available from: http:// www.ncbi.nlm.nih.gov/pubmed/26722564.

203. He W, Song H, Ding L, Li C, Dai L, Gao S. Association between IL-10 gene polymorphisms and the risk of ischemic stroke in a Chinese population. Int J Clin Exp Pathol. 2015 e-Century Publishing Corporation; [cited 2018 Dec 9];8:13489-94. Available from: http://www.ncbi.nlm.nih.gov/pubmed/26722562.

204. Béjot Y, Prigent-Tessier A, Cachia C, Giroud M, Mossiat C, Bertrand $\mathrm{N}$, et al. Time-dependent contribution of non neuronal cells to BDNF production after ischemic stroke in rats. Neurochem Int. 2011 [cited 2018 Dec 9];58:102-111. Available from: http://www.ncbi.nlm.nih.gov/pubmed/21074587.

205. Kowiański P, Lietzau G, Czuba E, Waśkow M, Steliga A, Moryś J. BDNF: a key factor with multipotent impact on brain signaling and synaptic plasticity. Cell Mol Neurobiol. 2017 Springer US; Available from: http://link.springer.com/10.1007/s10571-017. 0510-4

206. Qiao HJ, Li ZZ, Wang LM, Sun W, Yu JC, Wang B. Association of lower serum Brain-derived neurotrophic factor levels with larger infarct volumes in acute ischemic stroke. J Neuroimmunol. 2017 [cited 2018 Dec 12];307:69-73. Available from: http:// www.ncbi.nlm.nih.gov/pubmed/28495141.

207. Lasek-Bal A, Jędrzejowska-Szypułka H, Różycka J, Bal W, Holecki M, Duława J, et al. Low concentration of BDNF in the acute phase of ischemic stroke as a factor in poor prognosis in terms of functional status of patients. Med Sci Monit. 2015 International Scientific Information, Inc.; [cited 2018 Dec 12];21:3900-5. Available from: http:// www.ncbi.nlm.nih.gov/pubmed/26656843.

208. Yang L, Zhang Z, Sun D, Xu Z, Yuan Y, Zhang X, et al. Low serum BDNF may indicate the development of PSD in patients with acute ischemic stroke. Int J Geriatr Psychiatry. 2011 [cited 2018 Dec 12];26:495-502. Available from: http:// www.ncbi.nlm.nih.gov/pubmed/20845405.

209. Gottlieb M, Bonova P, Danielisova V, Nemethova M, Burda J, Cizkova D. Brain-derived neurotrophic factor blood levels in 
two models of transient brain ischemia in rats. Gen Physiol Biophys. 2013 [cited 2018 Dec 12];32:139-142. Available from: http://www.ncbi.nlm.nih.gov/pubmed/23531843.

210. Shen LH, Li Y, Chopp M. Astrocytic endogenous glial cell derived neurotrophic factor production is enhanced by bone marrow stromal cell transplantation in the ischemic boundary zone after stroke in adult rats. Glia. 2010 [cited 2018 Dec 12];58:1074-1081. Available from: http://www.ncbi.nlm.nih.gov/pubmed/20468049.

211. Hwang IK, Yoo KY, Kim DW, Lee BH, Kang TC, Choi SY, et al. Ischemia-related changes of glial-derived neurotrophic factor and phosphatidylinositol 3-kinase in the hippocampus: their possible correlation in astrocytes. Brain Res. 2006 [cited 2018 Dec 12];1072:215-223. Available from: http:// www.ncbi.nlm.nih.gov/pubmed/16412399.

212. Kuno R, Yoshida Y, Nitta A, Nabeshima T, Wang J, Sonobe Y, et al. The role of TNF-alpha and its receptors in the production of NGF and GDNF by astrocytes. Brain Res. 2006 [cited 2018 Dec 12];1116:12-18. Available from: http:// www.ncbi.nlm.nih.gov/pubmed/16956589.

213. Yang JP, Liu HJ, Yang H, Feng PY. Therapeutic time window for the neuroprotective effects of NGF when administered after focal cerebral ischemia. Neurol Sci. 2011 [cited 2018 Dec 12];32:433441. Available from: http://www.ncbi.nlm.nih.gov/pubmed/ 21409508.

214. Lee TH, Kato H, Kogure K, Itoyama Y. Temporal profile of nerve growth factor-like immunoreactivity after transient focal cerebral ischemia in rats. Brain Res. 1996 [cited 2019 Aug 28];713:199210. Available from: http:/www.ncbi.nlm.nih.gov/pubmed/ 8724992.

215. Hashimoto Y, Kawatsura H, Shiga Y, Furukawa S, Shigeno T. Significance of nerve growth factor content levels after transient forebrain ischemia in gerbils. Neurosci Lett. 1992 [cited 2019
Aug 28];139:45-46. Available from: http:// www.ncbi.nlm.nih.gov/pubmed/1407681.

216. Hasan N, McColgan P, Bentley P, Edwards RJ, Sharma P. Towards the identification of blood biomarkers for acute stroke in humans: a comprehensive systematic review. Br J Clin Pharmacol. 2012 [cited 2018 Dec 12];74:230-240. Available from: http:// www.ncbi.nlm.nih.gov/pubmed/22320313.

217. Jickling GC, Sharp FR. Blood biomarkers of ischemic stroke. Neurotherapeutics. 2011 [cited 2018 Dec 12]. p. 349-60. Available from: http://www.ncbi.nlm.nih.gov/pubmed/21671123.

218. Monbailliu T, Goossens J, Hachimi-Idrissi S. Blood protein biomarkers as diagnostic tool for ischemic stroke: a systematic review. Biomark. Med. 2017 [cited 2019 Aug 28]. p. 503-12. Available from: http://www.ncbi.nlm.nih.gov/pubmed/28598212.

219. Bustamante A, López-Cancio E, Pich S, Penalba A, Giralt D, García-Berrocoso T, et al. Blood biomarkers for the early diagnosis of stroke: the stroke-chip study. Stroke. 2017 [cited 2018 Dec 12];48:2419-2425. Available from: http:// www.ncbi.nlm.nih.gov/pubmed/28716979.

220. Fang C, Lou B, Zhou J, Zhong R, Wang R, Zang X, et al. Blood biomarkers in ischemic stroke: role of biomarkers in differentiation of clinical phenotype. Eur J Inflamm. 2018 SAGE PublicationsSage UK: London, England; [cited 2018 Dec 12];16:205873921878005. Available from: http://journals. sagepub.com/doi/10.1177/2058739218780058

221. Kim SJ, Moon GJ, Bang OY. Biomarkers for stroke. J Stroke. 2013 Korean Stroke Society; [cited 2019 Aug 28];15:27. Available from: http://www.ncbi.nlm.nih.gov/pubmed/24324937.

Publisher's Note Springer Nature remains neutral with regard to jurisdictional claims in published maps and institutional affiliations. 